Spring 4-25-2020

\title{
Occupational Therapy's Role in Matching Handlers and Assistance Dogs with Occupational Needs
}

Jyoti K. Tatla

University of St. Augustine for Health Sciences

DOI: https://doi.org/10.46409/sr.TKNI9101

Follow this and additional works at: https://soar.usa.edu/capstones

Part of the Educational Methods Commons, Occupational Therapy Commons, and the Other Rehabilitation and Therapy Commons

\section{Recommended Citation}

Tatla, J. K. (2020). Occupational Therapy's Role in Matching Handlers and Assistance Dogs with Occupational Needs. [Doctoral project, University of St Augustine for Health Sciences]. SOAR @ USA: Student Capstone Projects Collection. https://doi.org/10.46409/sr.TKNI9101

This Capstone is brought to you for free and open access by the Student Research at SOAR @ USA. It has been accepted for inclusion in Student Capstone Projects by an authorized administrator of SOAR @ USA. For more information, please contact soar@usa.edu, erobinson@usa.edu. 
OCCUPATIONAL THERAPY'S ROLE IN MATCHING HANDLERS AND ASSISTANCE DOGS WITH OCCUPATIONAL NEED

By

Jyoti K. Tatla

A Capstone Project Presented in Partial Fulfillment of the Requirements for the Degree of DOCTOR OF OCCUPATIONAL THERAPY University of St. Augustine for Health Sciences April 2020 
OCCUPATIONAL THERAPY'S ROLE IN MATCHING HANDLERS AND ASSISTANCE DOGS WITH OCCUPATIONAL NEED

\author{
By \\ Jyoti K. Tatla \\ has been approved
}

April, 2020

APPROVED:

Susan MacDermott, OTD, OTR/L, Doctoral Coordinator

Becki Cohill, OTD, OTR/L, Doctoral Coordinator

Erin Schwier, EdD, OTD, OTR/L, Program Director

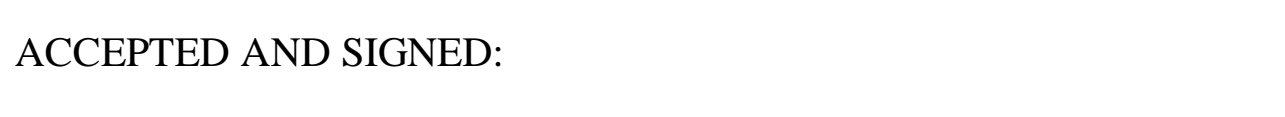

Susan MacDermott, OTD, OTR/L, Doctoral Coordinator

Becki Cohill OTD OTR/L

Becki Cohill, OTD, OTR/L, Doctoral Coordinator

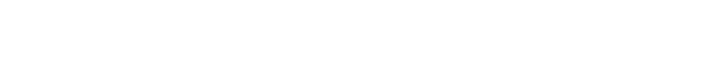

Erin Schwier, EdD, OTD, OTR/L, Program Director 
Table of Contents

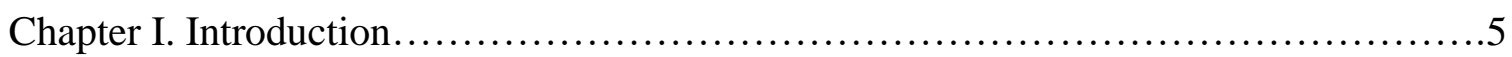

Statement of the Problem.....................................................

Purpose Statement.................................................... 9

Rationale for Proposed Project.......................................... 9

Significance of the Proposed Project.......................................10

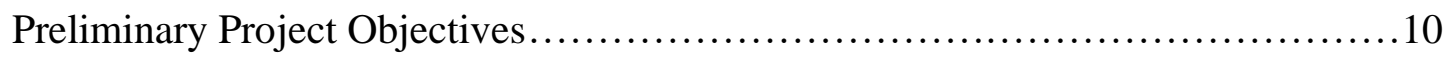

Definitions of Terms...................................................... 11

Assumptions........................................................

Limitations......................................................... 12

Delimitations........................................................ 13

Chapter II. Literature Review ............................................. 13

Occupation Therapists' Potential Role.........................................13

Current Practices Used to Assess Handlers and Assistance Dogs...................15

Negative Consequences of a Poor Match.................................... 16

Chapter III. Project Description.............................................17

Methods............................................................... 18

Chapter IV. Results and Analysis ...........................................19

Routines.............................................................. 19

Task Associated with New Occupations.....................................21

Physical Environment.................................................. 21

Observations of Current Matching Process .....................................23

Chapter V: Discussion and Conclusion......................................25 
Discussion.......................................................... 25

Implication for Occupational Therapy .........................................26

Limitations/Barriers.................................................29

Conclusion................................................................ 31

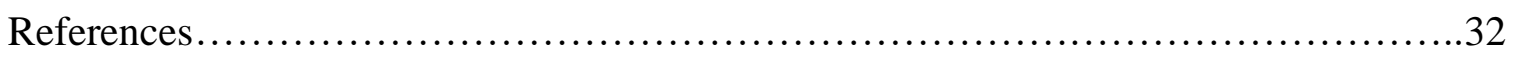

Appendix A Sample Interview Questions..........................................38

Appendix B Qualitative Themes..........................................52

Appendix C Learning Aids Cheat Sheet......................................54

Appendix D Practice Schedule..............................................55

Appendix E Role Changes.................................................56

Appendix F Modified Home Safety Assessment Checklist..........................57

Appendix G Learning Activities............................................66 
Occupational Therapy’s Role in Matching Handlers and Assistance Dogs with Occupational Needs

\section{Background}

Occupation therapy enhances and preserves participation in meaningful life activities (occupations) by acknowledging roles, habits, and routines in various settings (American Occupational Therapy Association [AOTA], 2014). Occupational therapists use their specific skills to design intervention plans based on the transactional relationship of the person, the value they put on occupation, and context (AOTA, 2014) Therapists can provide adaptions, modifications, or use objects within the environment to increase engagement for clients with a variety of needs that are disability- and nondisability-related (p. S1).

A framework was created to describe the central concepts of practice and basic tenets (AOTA, 2014). Domains within the framework include different types of occupations, such as activities of daily living (ADLs) and instrumental activities of daily living (IADLs), client factors, performance skills, performance patterns, and context and environment (AOTA, 2014, p. S4).

Andreasen et al. (2017) noted AOTA has found an important relationship between people and their animals and therefore considers care of pets an IADL. Therapists also use animal-assisted therapy (AAT) interventions to facilitate skills for independent functioning and occupational engagement (Andreasen et al., 2017). Such interventions can include "promotion, remediation/restoration, maintenance, or prevention" (Andresen et al., 2017, p. 2). AAT and occupational therapy share the same goal to improve 
"attention skills, social skills, participation in play, self-esteem, and reducing anxiety, loneliness and isolation” (Andresen et al., 2017p. 3).

In the past two decades, there has been an increase in the use of assistance dogs to improve health, function, and companionship (Walther et al., 2017). There are three types of assistant dogs: service dog, guide dogs, and hearing dogs (Assistance Dogs International, Inc., 2019). Service dogs assist people with disabilities that are not vision or hearing-related (Assistance Dogs International, Inc., 2019). Guide dogs assist people who are blind or visually impaired and always use a harness and U-shaped handle to communicate. Guide dogs provide safety, while the human provides directional commands (Assistance Dogs International, Inc., 2019). They are the most needed of any assistance dog and must make accurate decisions regardless of their handler's cues to provide safety (Audrestch et al., 2015). Hearing dogs assist people who are hearing impaired by notifying of household sounds (i.e., alarm clock, smoke alarm, telephone, etc.) and leading handlers to the source of the sound (Assistance Dogs International, Inc., 2019). Hearing dogs are trained to identify up to seven different sounds (Audrestch et al., 2015, p.470).

Service dogs provide assistance for a variety of needs especially for those who have balance challenges, diabetic issues, seizures, and mental health disorders (Audrestch et al., 2015; Crowe et al., 2014; Winkle, Crowe, \& Hendrix, 2012). Some benefits of service dogs include energy conservation, preventing further injuries, obtaining supplies, providing a counterbalance, and detecting and responding to medical emergencies for help (Winkle et al., 2012). 
Therapy dogs do not have the same legal access as assistance dogs and are there to provide comfort and affection to people who may have experienced trauma or disaster (Reisen, 2019). The American with Disabilities Act (ADA) Title II and III (U.S. Department of Justice, 2015) permits assistance animals to accompany anyone with a disability into public spaces because they are specially trained to perform tasks.

This project will focus on the incorporation of occupational therapy during the process of matching assistance dogs to handlers. Although assistance dogs offer a variety of benefits for individuals with different needs, matching a person with a suitable dog is not always successful the first time. Research by Lloyd, Budge, Grow, and Stafford (2016) found that unsuccessful matches were possibly due to a dog's behavior (workrelated and non-work related) or because of the handler's response. Environments noted as "non-work related areas," included home and social contexts, and were determined to be just as important factors as mobility and independence when considering potential matches (Lloyd et al., 2016). Occupational therapy can impact this process through clinical reasoning by organizing and synthesizing objective data a client may provide (Schell, Gillen, \& Scaffa, 2014).

Occupational therapists are skilled at activity analysis during an evaluation and can take into account skills involved in the activity, personal goals, abilities, and/or body structure (AOTA, 2014). Therapist can provide comprehensive evaluations in an individual's home, workplace, and community (Schell et al., 2014), by adapting or modifying environments, to address barriers and obstacles (AOTA, 2014). These modifications can make it easier for an assistance dog and handler to form their new bond as they engage in new activities and routines (AOTA, 2018; Fairman \& Huebner, 2001). 
For example, a therapist can modify everyday items such as leashes, dog doors, and feeding equipment, to ensure proper care for the dog (Rintala et al., 2008). This process would also include identifying assessments that are being utilized at assistance dog programs to understand the needs of clients before training a dog (Zapf \& Rough, 2002). Identification by an occupational therapist of key factors for a successful match can mitigate time, costs, injuries, and improve the overall quality of life for handlers (Crowe et al., 2014; Rintala et al., 2008).

Occupational therapist can provide services across the lifespan, concentrating on important occupations that are meaningful to the individual, and making the evaluation process client-centered (AOTA, 2018). Finally, therapists can teach self-advocacy and directly advocate for their clients, supporting them in becoming better educated about assistance dogs and programs. Doing so will help clients overcome barriers before, during, and after the placement process (Winkle et al., 2012).

\section{Statement of the Problem}

The successful matching of an assistance dog with their handler is crucial for quality of life. It ensures that handlers have their needs met for safety and performance of necessary tasks (Rintala, Matamoros, \& Seitz, 2008). For example, successful matches can increase satisfaction with tasks, support social engagement, and reduce taxing limb efforts (Crowe et al., 2014; Hubert et al., 2013; Martin-Lemoyne et al., 2016).

However, due to limited research on the matching process, many handlers are not able to get successfully matched and may end up going through the matching process numerous times (Lloyd et al., 2016). This need to go through multiple matching processes frustrates handlers, increasing cost and injuries (Winkle et al., 2012). Personal 
problems could include panic attacks, failures to take medication, drops/spikes in blood sugar, and falls (Disabled Resource Services, 2019).

In response to poor matching of handlers and assistance dogs, this project proposes to investigate the need for an occupational therapist during the evaluation process to identify factors that may not be seen or identified by the original team or assistance dog programs.

\section{Purpose Statement}

The purpose of this proposed project was to assess and observe the current matching process and to identify the role of an occupational therapist in aiding the evaluation process with potential handlers and assistance dogs.

\section{Rationale for Proposed Project}

Matching a handler with his or her assistance dog is not just about physical skills. Building a relationship of close companionship requires an understanding of many elements. Through the framework of Ecology of Human Performance (EHP), the relationship between a person and his or her environment is explored because it affects human performance (Dunn, Brown, \& McGuigan, 1994). The EHP framework is inclusive and should be examined before implementing interventions (Dunn et al., 1994).

Before an assistance dog enters a handler's home, occupational therapists can adapt/modify contextual features to improve task performance for a person and his or her assistance dog (Dunn, 2008). These modifications can include assistive devices, ramps, and grab bars (Dunn, 2008). Each space in the home must be considered to make daily tasks easy to complete. Some modifications that an occupational therapist can aid with are abiding by ADA requirements (Elliot \& Hogle, 2013). Examples could include 
ensuring the driveway and garage have adequate space, the path to the door is clear of shrubs, and doorways are wide enough (Cook \& Polgar, 2015). Additional actions might be decluttering hallways, placing tugs on the refrigerator and lower cabinets, and putting bins in the living room to create more space (Cook \& Polgar, 2015). Designing an area where the assistance dog can sleep is another critical component of the environment. This enhances quality of sleep, safety, and ease of access for the handler (Crowe \& Nguyen, 2018). These considerations and associated actions set up an environment for success by enhancing contextual cues and minimizing distractions for both handlers and assistance dogs (Dunn et al., 1994).

\section{Significance of the Proposed Project}

Assuring the optimal match between a handler and a dog is significant because it increases the quality of life of the handlers. Optimal matches can be achieved by adding occupational therapy to strengthen the evaluation process. Creating better matches will reduce financial costs (paid assistance), time, resources, and possible injuries (Lloyd et al., 2016; Rintala et al., 2008). As handlers gain more independence, it can increase community integration, social interactions, and energy conservation to complete meaningful tasks (Rintala et al., 2008).

Even though occupational therapists are often seen using dogs as a modality during a session, entering the field earlier in the matching process can provide more opportunities for occupational therapists to collaborate with a new team of professionals, provide further input, and create new roles such as consultants.

\section{Preliminary Project Objectives}

During this project the main goal was to identify the potential opportunities for 
occupational therapists during the evaluation process for matching handlers and assistance dogs. Preliminary objectives included:

- Completing a needs assessment of current matching processes at different dog training facilities.

- Interviewing handlers before, during, or after the matching process to identify environmental, social, physical, and mental barriers.

- Evaluating literature to understand the needs of certain populations who require an assistance dog.

- Identifying current or potential assessments that can be incorporated into the evaluation process.

- Identifying and organizing recommendations based on literature review, observations, interview, and assessment results.

- Synthesizing recommendations to enhance the matching process and communicating them to both training program staff and handlers.

\section{Definitions of Terms}

For this capstone project, context and environment played a vital role, specifically when looking at training techniques. Context referred to a "variety of interrelated conditions that are within and surrounding the client," (AOTA, 2014, p. S28) while environment referred to the "external physical and social conditions that surround the client and in which the client's daily life occupations occur" (p. S28).

Animal-assisted therapy was a "goal-directed intervention wherein the animal is used during the treatment process" (Andreasen et al., 2017, p. 1). This was observed during the matching process between a handler and dog. Matching included a "trained 
dog to its handler, the training of the handler and dog as a team, and ongoing follow-up" (Lloyd et al., 2016, p. 2). The matching process was one of the main focuses of this project. Handlers were considered people who used dogs to provide them with services, facilitator of training, or a person who had right and ownership to the dog (Pierce, 2018). Successor dog is another assistance dog placed after the first assistance dog has retired due to old age, health problems, or death (Dogs for Good, 2020). This capstone project explores the reason why participants get a successor dog and their experiences the second time around.

\section{Assumptions}

This project made the assumption that handlers and assistance dogs are not always matched properly the first time at training programs, leading to increased costs, wasted resources, and reduced quality of life (Lloyd et. al, 2016). Another assumption was that some programs only included a two-week training for handlers and assistance dogs (Canine Support Teams Inc., n.d.), which was not sufficient because it does not include the home environment. The last assumption was that potential handlers were experiencing injuries, reduced task performance, and participation in daily activities while waiting to be matched with an assistance dog (Crowe et al., 2014) and after being placed (Lloyd et al., 2016).

\section{Limitations}

A large limitation in this project was limited time in observing and engaging in multiple sites due to the lack of hours the programs provided. Programs provided twoweek trainings for handlers and their potential assistance dogs, but not all programs were observed at different sites leading to a lack of data. Programs also provided limited 
trainings a year; meaning observation hours was limited and conflicted with other sites.

Lastly, participants may not have seen a problem in their matching process or had barriers to discuss before, during, or after receiving an assistance dog.

\section{Delimitations}

Within this project there were delimitations to consider. It was decided that the type of assistance dog (service versus guide dog) and its' ability would not be an exclusion because of the need for multiple sites. This lack of exclusion criteria produced inconsistent data and difficulty decoding each participant's information in an organized manner. The project focused on the matching process of how handlers and assistance dogs were paired throughout programs. Lastly, this project observed training techniques a handler learned within the program but not what assistance dogs learned prior to meeting their potential handlers.

\section{Chapter II. Literature Review}

To understand the purpose of this project, it is important to examine different themes that warrant occupational therapy's involvement in the matching process. The themes found from the literature include: 1) occupational therapists' potential role in the matching process, 2) the current practices used to assess handlers and assistance dogs, and 3) negative consequences of a poor match.

\section{Occupation Therapists' Potential Role}

According to the American Occupational Therapy Association (AOTA), occupational therapists often incorporate animal assisted interventions (AAIs) into their practice by providing animal-assisted therapy (AAT), education, engagement in activities, and increasing support to improve overall health and wellness (2019). 
Education can include learning different skills an assistance dog can provide, becoming familiar with local dog training organizations, and understanding if a client is a good candidate to receive an assistance dog (Winkle et al., 2012). Although occupational therapists use animals as a modality, they are not commonly seen in the evaluation process when an individual is matched with an assistance dog.

Fairman and Huebner (2001) claim that occupational therapists should have ties with the assistance dog industry because they fall into the domain of occupational therapy. This study stated that respondents desired alternative ways to complete daily living skills during the training period and would benefit from occupational therapy services (Fairman \& Huebner, 2001). Therapists can collaborate with dog trainers to make "referrals, analyze tasks, grade training, and/or provide alternative modifications" (Fairman \& Huebner, 2001, p. 50). Additionally, they have the ability to screen and evaluate potential handlers' performance in functional tasks and abilities to care for an assistance dog (Fairman \& Huebner, 2001; Vincent, Poissant, Gagnon, \& Corriveau, 2016; Winkle et al., 2012; York \& Whiteside, 2018). Together, the trainer and occupational therapist can create customized commands and skills during a training session to support a successful assistance dog-handler partnership (Fairman \& Huebner, 2001).

Occupational therapists can intervene at any level (person, activity, and/or environment) to address barriers that may occur before, during, and after the placement process (Winkle et al., 2012). Some studies have found that the environment can impact how well a handler and dog build a successful partnership (Lloyd, Budge, Grow, \& Stafford, 2016; Vincent et al., 2016; Winkle et al., 2012). Many potential handlers may 
not be ready financially, physically or mentally for this new transition. Therapists can address the responsibilities of owning an assistance dog, such as grooming, exercise, doctor's visits, and toileting (Camp, 2001; Vincent et al., 2016).

\section{Current Practices Used to Assess Handlers and Assistance Dogs}

The do dog industry currently does not have consistent standards that assure quality in assessments or training (Vincent et al., 2016). One reason could be competition between programs for clients (Winkle et al., 2012). Assistance dog programs are slowly changing because of the establishment of Assistance Dogs International, a non-profit organization facilitating communication, education of the public, and setting standards for trainers and recipients (Winkle et al., 2012).

A few core assessments are currently used by programs to understand potential handlers. Vincent et al. (2016) compared the outcome measures of three tools: the Impact on Participation and Autonomy (IPA) scale, Keele Assessment of Participation (KAP), and Participation Scale (P-Scale). The IPA determines benefits an assistance dog may provide (Vincent et al., 2016). Domains addressed include self-care, interpersonal relationships, community, social activities, and civic life (Mudge, Rewi, \& Channon, 2017, p. 77). Vincent et al. (2016) chose IPA as a better outcome measure than the KAP and P-Scale. However, the IPA lacks key determinants and predictors that lead to recommendations. Since matching a specific assistance dog to a unique user is complex, one solution Vincent el al. (2016) suggested was trial periods, when the user could explore the assistance dog's potential usability in functional tasks and receptiveness to the environment (Vincent et al., 2016).

Another example of inconsistency early in the process that can interfere with the 
success of a handler-dog match is puppy training. Research findings suggest that there is a lack of uniformity when it comes to stimuli, age of testing, and form of evaluation (Asher et al., 2013). The Puppy Profiling Assessment (PPA) measures how puppies respond to a series of controlled stimuli and their reactions (Asher et al., 2013). Success is measured by a lack of response to the environment. The PPA can reduce training costs and withdrawal of dogs from a training program because of other rigorous assessments (Asher et al., 2013). The estimated withdrawal rate is $35 \%$ (p. 438).

Organizations should use measures that are both psychometric and functional when assessing the benefits of well-trained assistance dogs. Documentation with outcome measures could increase funding to support ongoing training and program development while addressing barriers within the industry (Mudge et al., 2017).

\section{Negative Consequences of a Poor Match}

When discussing assistance dogs, most literature examines their benefits, such as increased socialization, independence, satisfaction with tasks, mobility, and reduced pain (Camp, 2001; Champagne, Gagnon, \& Vincent, 2016; Crown et al., 2014; Fairman \& Huebner, 2001; Hicks \& Weisman, 2015; Martin-Lemoyne et al., 2016; Ng, James, \& McDonald, 2000; Rintala et al., 2008; Vincent et al., 2015; Vincent et al., 2016). However, a poor partnership can have detrimental effects, causing emotional distress (Audrestch et al., 2015), reducing mobility, quality of life, and training program resources (Lloyd et al., 2016). Dog training programs costs up to $\$ 20,000$ for training puppies (Service Dog Certifications, 2017). A study of 50 partnerships of people with one or more dogs (118 pairings) found that 43 dogs were returned due to dog-related behaviors, work and non-work behavior, physical causes, and the handler's behavior 
(Lloyd et al., 2016). Lloyd et al. (2016) also noted that some handlers chose to keep their dogs even though they knew they were poorly matched, thus reducing the quality of life for both parties.

\section{Chapter III: Project Description}

The two major purposes of this project were: 1) to observe and assess the current matching process of assistance dog programs and 2) identifying occupational therapy’s role in aiding the evaluation process. This project included three assistance dog programs in California: Guide Dogs for the Blind (GDB), Canine Companions for Independence (CCI), and Canine Support Teams, Incorporated (CST). The project applied the framework of Ecology of Human Performance (EHP) to understand clients, their environments, and possible barriers in the process of obtaining an assistance dog.

This project engaged participants in in-depth interviews to gather data on their perspective(s) at any point of obtaining an assistance dog. Interviews, ideally took place at the dog program site for approximately 45 minutes to an hour from January to April 2020. If necessary, original or follow-up interviews would be conducted via Skype. Interview questions were closed and open-ended, examining the participant's life (routines and tasks associated with new occupations), their need for an assistance dog, tasks in which the dogs will aid, disability (if comfortable), need for additional support, costs of obtaining/maintaining a dog, adaptive tools needed, and home environment. See Appendix A for sample interview questions.

Participants would be recruited from the three locations previously mentioned at any point during the process of attaining an assistance dog. Inclusion criteria required participants to have completed an application at their dog program site prior to being 
interviewed. The number of total participants was contingent upon program directors and their ability to recruit. This project did not limit participation based on age, gender, or type of assistance dog.

Additionally, to understand the value of this project, administrators and staff of the three dog programs were to be provided with presentations of data and identified themes. They were asked to take a short Likert-scale survey afterwards to determine if this project benefited their site.

\section{Methods}

This capstone experience included three assistance dog programs, GDB, CCI, and CST. CCI and CST both provided service dogs for a variety of disabilities, while GDB only provided guide dogs for individuals who are blind or have visual impairments. During this project, only CCI and CST two-week team training sessions were observed. The GDB could not be observed due to the pandemic of coronavirus disease (COVID19). The GDB closed their California and Oregon campuses to volunteers, guests, and clients. Therefore, training was cancelled and clients were sent home without guide dogs. All California residents are required to "shelter-in-place" until undetermined date.

A total of 25 participants were recruited for interviews from early February to late March. Two participants for CST were recruited during a two-week training in October 2019, and two participants were recruited by word of mouth from the principal investigator's mentor, who also received her dog from CST. Ten participants were recruited from CCI during a two-week training, and one participant was recruited by a peer. All ten participants from GDB were recruited by the site supervisor. The CCI interviews took place at their headquarters in Santa Rosa after training sessions. The 
remaining interviews were conducted over the phone.

Interview questions were adjusted to be site-specific due to differing training methods, costs, and the results of previous evaluation information. Site supervisors for CCI and GDB gave access to their participant files and applications in order to reduce repetitive interview questions. Interviews averaged from 20 to 35 minutes. The majority of participants were from California, except half of the participants from GDB, who were from Montana, Minnesota, Montana, Wisconsin, Wyoming, and Canada.

\section{Chapter IV: Results and Analysis}

This chapter provides results from the capstone project and an analysis of the findings. Three themes were identified: routines, tasks associated with new occupations, and physical environment (successor versus first time handler). For this section, direct quotes from project participants will be indicated as "P" (for participant) with a number and the acronym for location. See Appendix B for qualitative themes. In addition, observations of key elements of the matching process at each site will be discussed.

\section{Routines}

After data analysis of interview transcripts from 25 participants in three different training facilities, the first notable theme found was a change in routines (American Occupational Therapy Association [AOTA], 2014). Before receiving an assistance dog, participants shared that their routines would change. Statements included: "I'll have to watch less television and play more" (P4 Guide Dogs for the Blind [GDB]) and "I will

have to wake up earlier before school for relieving and walking the dog" (P5 GDB). One participant (P10 GDB) noted that, because of his unemployment, "the hard part right now 
is that I don't have a consistent schedule, which makes it difficult for [guide dog's name], more than me."

Some participants had to wait to retrieve their successor dog. Individuals at Canine Companions for Independence (CCI) shared that certain occupations within their routines had changed while waiting for their successor dog because they no longer could work with their retired assistance dog by: using a power chair rather than a manual chair to reduce shoulder fatigue (P5 CCI), asking their significant other for more assistance (P1 $\mathrm{CCI}$ ), hiring paid help (P2 CCI), and finalizing plans for adoption of their first dog (P4 $\mathrm{CCI})$.

Additionally, it was noted that many families had a difficult time adjusting to their new assistance dog. One individual expressed that their partner felt overwhelmed at times with having their successor dog and new assistance dog within a small apartment, and therefore no longer wanted to incorporate a pet dog into their routine (P10 CCI). Another claimed that he had to remind his children daily to take their toys, shoes, and food off the table to reduce additional obedience training for his assistance dog (P10 GDB). The hardest thing for families to adjust to was not being able to create a bond with the new assistance dogs during the first six to twelve months (P7 CCI; P10 GDB; P6 GDB; P2 Canine Support Teams [CST]). Creating new family boundaries was essential to reduce handler confusion for the assistance dog.

These observations support the AOTA's (2014) assertion that a change in routine can either promote or damage health. In this case, the affected parties included the handlers, assistance dogs, and support systems. A support system can be defined as anyone helping with activities involving the assistance dog, such as significant other, 
children, siblings, or neighbors.

\section{Task Associated with New Occupations}

The second theme recognized was changes in tasks associated with new occupations for significant others and families. Although many participants stated that they were independent enough to care for their assistance dog, others admitted that specific responsibilities would be taken over by their support system. One participant, who had limited use of her hands, said, "My family will help with picking up poop, and my sister is a dog groomer, so she'll help with grooming. The kids will eventually learn more responsibilities as we go" (P7 CCI). Five participants, who all used wheelchairs, shared that their significant others and families would be helping with exercise when needed due to balance issues and pain (P1 CCI; P5 CCI; P8 CCI; P9 CCI; P13 CCI).

Addressing tasks associated with new occupations for the client's support network creates a meaningful and purposeful life (AOTA, 2014), and eases the responsibility for handlers, who often have comorbid diagnoses (Andreasen et al., 2017). This finding was echoed by the AOTA's (2014) assertion that the addition of a new member to the home creates co-occupations, which supports the "client's engagement in context in relationship to significant others" (S6).

\section{Physical Environment}

The Ecology of Human Performance (EHP) model, which emphasizes the interaction between a person and their environment, was the guiding theory for this capstone project (Dunn, Brown, \& McGuigan, 1994). Two themes, successor and firsttime handlers, were found under home environment when discussing home evaluations.

Successor handlers. The results of the needs assessment revealed that handlers 
with successor dogs were better prepared the second time around compared to first time users. For example, handlers, who used wheelchairs, did not express a need for a home evaluation (P1 CCI; P2 CCI; P5 CCI; P8 CCI, P10 CCI). They had adapted their homes according to ADA requirements when they were first diagnosed at a younger age; half had subsequently retired (P1 CCI; P5 CCI). This population included participants with spinal cord injuries, muscular dystrophy, cerebral palsy, and undiagnosed movement disorder, all from Canine Companions for Independence (CCI). Although users were not open to home evaluation for their successor dogs, they all mentioned they would have been with their first assistance dog. One claimed, "I would have been open to this idea; you don't know what you're getting into with the first dog" (P10 CCI). Another stated, "It's beneficial to understand your own limitations, since my disease is progressive" (P4 CCI). Limitations include knowledge of where to put feeding supplies, placing tugs on different handles, and conserving energy.

First-time handlers. First-time handlers, which included CCI and CST handlers, were open to home evaluations. It is important to note that CCI and CST do not provide home evaluations in their initial application process. One participant stated, "My whole world shook up, I had to make room for a large dog in the house, which meant big bed and big toys" (P4 CST). Another was not aware initially who was going to aid him in relieving his assistance dog and picking up excrement from the community college campus. He replied: "I guess my aide can help me or my friends" (P9 CCI). Participant P7 CCI, a mother, was open to a home evaluation because the nature of her home was unpredictable, with three children under the age of twelve.

Participants from GDB agreed to in-person home interviews, which included a 
home evaluation. Out of the ten participants, only two (P3 GDB; P7 GBD) claimed that their instructors told them about environmental changes. All the other eight participants (P1 GDB; P2 GDB; P4 GDB; P5 GDB; P6 GDB; P8 GDB; P9 GDB; P10 GDB) claimed that they did not need to make any environmental changes to their homes. One mentioned, "They didn't walk around the house much, just saw the kitchen and living room" (P4 GDB).

During training, a participant described the physical changes he was going to make at home:

There's a lot I didn't realize, I'll get an actual kennel, make it feel more like home....get basic necessities like food bins because I don't have that...if I move now, I have different considerations like a closed area for my dog to run in, since I live in a small apartment (P7 GDB).

Data analysis revealed that participants felt there was no relationship between environment and a successful match. However, factors contributing to getting a successor dog were reflective of literature (Lloyd et al., 2016), such as behavioral problems like reactivity with other dogs $(\mathrm{P} 1 \mathrm{CCI})$, sudden death $(\mathrm{P} 2 \mathrm{CCI})$, reaching retirement age $(\mathrm{P} 4$ CCI; P5 CCI; P6 GDB, P4 CST), and health problems of the previous assistance dog (P2 CCI).

\section{Observations of Current Matching Process}

Observations were done at CST and CCI during their two-week team trainings. The CST had seven clients; two were successors who only stayed for the first week of training. The program focused immediately on introducing service dogs and allowed clients to take them home on the first night. Instructors based matches on the initial phone 
interview and personalities of the handler and service dog. During the observation, one participant had to be matched twice due to poor temperament of the dog and lack of responsiveness. Instructors claimed they had a $95 \%$ success match rate.

The first step CCI took was during their on-site interview. Clients were asked to demonstrate their handling skills with a fake dog, voice inclination, leash correction, and learning style. During the training, 14 clients attended. Only five were first-time handlers. Clients were broken up into two groups of seven and placed in different classrooms. The CCI used Excel data sheets to match potential handlers to service dogs. Instructors had one to two dogs in mind for each handler and completed five practice rounds for the first two days of training. The Excel sheet compared the handler's skills, service dog skills, if a dog could pull a wheelchair (specialized skill), personality, and temperament. Matches were not finalized until the third day, after comparing data of the handler and service dog. Instructors claimed they had a $95 \%$ success match rate.

Although there was no observation at GDB, the principal investigator did participate in a round table discussion two weeks before training about the dog matching process. This discussion included the California and Oregon campuses and was intended to increase knowledge for apprentice instructors. According to the conversation, the matching process consisted of four factors: pace, orientation and mobility training, and control. The pace was captured through a mobile application called Map My Walk, which recorded miles per hour, time, and distance. For orientation and mobility training, the amount of advanced training a client had over the past years was correlated to the level of traveling and safety skills. Lastly, the control factor was graded on a scale that ranged from 1 (poor management) to 4 (above-average management). In all of these factors the 
client and guide dog must match in order to be paired together. Instructors claimed they had a $95 \%$ success match rate.

\section{Chapter V: Discussion and Conclusion}

\section{Discussion}

The purpose of this capstone project was to assess and observe the current matching process at three assistance dog programs and to identify occupational therapy's role in aiding the evaluation process.

This project affirmed that occupational therapists should have ties with dog training facilities. Research has shown that therapists can address different activities in alternative ways (Fairman \& Huebner, 2001). Although it was found that environment did not impact matches within this project, past research claimed it was important foundation for building successful partnerships (Lloyd, Budge, Grow, \& Stafford, 2016; Vincent et al., 2016; Winkle et al., 2012). This project revealed that participants, specifically successors, were well addressed when it came to responsibilities of owning an assistance dog by past experiences, financially ready due to retirement, and mentally eager to create a new companionship (Camp, 2001; Vincent et al., 2016). First-time handlers could still benefit from therapists to focus on new responsibilities.

Research showed that the dog training industries still do not have consistent standards with assessments and training strategies (Vincent et al., 2016), which was directly observed during this project. While large facilities used standards by Assistance Dogs International, smaller facilities may not due to annual accreditation membership fees (Assistance Dogs International, 2020). Lack of uniformity produces different training methods, costs, and handler expectations. 
Lastly poor partnerships between handlers and assistance dogs did reveal reduced mobility and reduced quality of life (Lloyd et al., 2016), for a small number of participants. It was found that reactive dogs reduced mobility in the community and could cause physical harm to their handlers by making them fall off their wheelchairs.

\section{Implications for OT}

The assessments revealed that most participants had a difficult time absorbing lecture material and would have preferred more one-on-one time with instructors or additional learning aids. Learning aids could have included "cheat sheets" for all the commands they had learned throughout the weeks (see Appendix C for learning aids cheat sheet), a copy of the lecture materials, and recorded lectures that they could watch later at home if they had forgotten.

Advanced learning-theory and clicker training were another difficult concept for participants to grasp, when teaching their assistance dog new commands. New handlers may have benefited from a website link that provided additional videos of what commands were combined, the break down of each step, the time it took, and obedience training.

Next, addressing travel training and working through a large crowd was a topic minimally discussed. Although instructors suggested keeping assistance dogs at home during hectic outings, addressing these issues would have benefited members who had no other choice by giving them tools to address barriers. Overall, all sites could have benefited from enhanced knowledge of their client's learning styles, diagnoses, and needs.

The findings presented in this project reveal that each individual has unique needs 
that should be understood when being paired with an assistance dog. Occupational therapists can aid in the evaluation process by addressing a variety of concerns a client may have directly within the training facilities, homes, and communities as a preventative measure. Occupational therapists can examine the change in performance patterns that come along with being paired with an assistance dog (Fairman \& Huebner, 2001; Vincent, Poissant, Gagnon, \& Corriveau, 2016; Winkle et al., 2012; York \& Whiteside, 2018).). The two themes found within interviews revealed that routines and tasks associated with new occupations changed the most for handlers and their support systems. Occupational therapists can problem-solve routines by having clients establish and practice new routines prior to getting an assistance dog. Examples include setting up alarms to practice walking, feeding, and relieving a dog multiple times a day (see Appendix D for practice schedule). During this practice period, therapists can address any unforeseen events and help incorporate any adaptive equipment needed for the assistance dog.

Another area occupational therapists understand well is new occupations associated with caring for an assistance dog with an individual and group (AOTA, 2014). Introducing a new family member can change tasks not just for the handler, but also for family and friends. Therapists can also establish new tasks for individual members of the family early on reducing difficult transitions or errors in occupational performance (Schell, Gillen, \& Marjorie, 2014). See Appendix E for task changes handout.

The most significant role occupational therapists can play within the evaluation is performing home evaluations for first-time handlers. See Appendix F for a modified home safety assessment checklist instructors can use. Neither CCI nor CST completed 
home evaluations during their application process, although CCI did require applicants to take pictures of their home to include in their applications. A client's home can either "support or present barriers to participation" (American Occupational Therapy Association [AOTA], 2014, p. S8). Dunn, Brown, and McGuigan (1994) claimed that enhancing contextual cues and minimizing distractions created a successful environment. As mentioned previously, therapists can address adaptations to the environment such as:

- Environment where the assistance dog will sleep

- Placement of food bins to increase energy conservation

- Establishing a space for relieving

- Rearranging furniture for specific commands

- Addressing harmful plants in the front yard/backyard

- Addressing counter clutter or foot traffic

One way Guide Dogs for the Blind can address home evaluations is using clientcentered assessment forms that include different areas of the home (American Occupational Therapy Association [AOTA] 2018). Instructors can leave copies of the assessment forms behind so clients can remember what changes to make. This assessment could consist of topics such as: clutter, electric cords, unstable furniture, lack of space, meal preparation safety, unsecured items, etc. (University of Buffalo, 2017). See Appendix F for a modified home safety assessment checklist.

Future areas of research and projects could include exploring telehealth within dog training facilities to complete home evaluations if traveling and staff are not 
available. According to literature and recent events, telehealth business within the United States is expected to grow into a $\$ 2.8$ billion industry (Chiron Health, 2019). Neither CST and CCI incorporate home evaluations in their interviews; occupational therapists can use telehealth to communicate with a client from a different location. This delivery of care can address the clients' natural environment, while reducing staff travel (Gately, Trudeau, \& Moo, 2020).

Another area for future research could include using occupational therapist as consultants before team trainings. Occupational therapists can educate training staff about a diverse range of disabilities and how to address obstacles that may come up. Therapist can also provide staff with learning activities to better understand their client's needs. See Appendix $G$ for learning activities.

Lastly, this project could have done a better job at exploring changes in roles, of handlers and the support system. Interview questions were focused around routines and mainly the home environment. Reasons could have been a lack of time writing sitespecific questions and wanting to center the research on the framework of Ecology of Human Performance (EHP). Future occupational therapists can play a large part when addressing role changes that impact the handler and support systems' identities, values, and beliefs (AOTA, 2014).

\section{Limitations / Barriers}

There were several limitations to this capstone project that included: small sample size, different types of assistance dogs, and not interviewing enough first time handlers.

This capstone project included 25 participants. The ideal number of participants would have included five participants from before, during, and after team training to 
learn in-depth perspectives at each stage from three different dog-training facilities. CST and CCI could not provide enough participants due to logistics and small training staff. Limited participants were provided by GDB because of coronavirus disease (COVID-19), canceling team training. A greater participant size would have provided a better range of data from each site.

Additionally, CCI and CST both provided service dogs for individuals with an array of disabilities including: PTSD, hypermobility spectrum disorder, hereditary angioedema, cerebral palsy, spinal cord injuries, amputees, movement disorder, and muscular dystrophy. The GDB provided guide dogs for individuals with visual impairments that included: retinitis pigmentosa, Vogt-Koyanagi-Harada disease, detached retinas, and Stargardt disease. These two types of dogs provided completely different needs, which could have also skewed the information gathered. The GDB participants only used their dogs for mobility, while CCI and CST used their service dogs for a variety of tasks. This led to last minute changes when writing interview questions, due to differing training strategies, costs, and prior knowledge of participants. Writing questions after experiencing training would have led to more in-depth questions.

Out of the 25 participants, seven were experienced successor handlers. Although experienced handlers were not initially interested in in-home evaluations, this long period could have made them forget the obstacles they had experienced the first time. Another likely reason is that participants did not see any limitations or barriers while pairing with their first assistance dog. The project would have benefited if all handlers were first time users. 


\section{Conclusion}

Several key findings from this project revealed a need for occupational therapy within the evaluation process and two-week team training. Although participants subsequently continued with successful matches, enhancing the programs could increase quality of life and ease of information attainment for participants. Each site revealed that participants had a difficult time learning material and would benefit from different approaches of interventions that included adaptation and modification (AOTA, 2014). Doing so will help clients overcome barriers before, during, and after the placement process (Winkle et al., 2012). Therapists can also collaborate with training staff to provide alternative modifications within the home and have in-depth discussions about changes in performance patterns. Furthermore, the findings reflect previous literature that occupational therapy can enhance and preserve the pairing of a handler and their assistance dog (Andreasen et al., 2017; Bibbo, Rodriguez, \& O’Haire, 2019; Crowe et al., 2014; Fairman \& Huebner, 2001; Winkle, Crowe, \& Hendrix, 2012, Zapf \& Rough, 2002). 


\section{References}

American Occupational Therapy Association. (2018). About occupational therapy. Retrieved from https://www.aota.org/About-Occupational-Therapy.aspx American Occupational Therapy Association. (2014). Occupational therapy practice framework (OTPF): Domain \& process ( $\left.3^{\text {rd }} \mathrm{ed}.\right)$. The American Journal of Occupational Therapy, 68 (Supplement 1), S1-S51.

American Occupational Therapy Association, Inc. (2019). Frequently asked questions (FAQ): Animal assisted therapy for occupational therapy practitioners. Retrieved from https://www.aota.org/Practice/Rehabilitation-Disability/service-animalassisted-therapy/FAQ.aspx

Andreasen, G., Stella, T., Wilkison, M., Szczech Moser, C., Hoelzel, A., \& Hendricks, L. (2017). Animal-assisted therapy and occupational therapy. Journal o Occupational Therapy, Schools \& Early Intervention, 10(1), 1-17. https://doi.org/10.1080/19411243.2017.1287519

Asher, L., Blythe, S., Roberts, R., Toothill, L., Craigon, P. J., Evans, K. M., Green, M., \& England, G. C. W. (2013). Research: A standardized behavior test for potential guide dog puppies: Methods and association with subsequent success in guide dog training. Journal of Veterinary Behavior: Clinical Applications and Research, 8, 431-438. https://doi.org/10.1016/j.jveb.2013.08.004

Assistance Dogs International Inc. (2019). ADI terms and definitions. Retrieved from https://assistancedogsinternational.org/resources/adi-terms-definitions/

Assistance Dogs International Inc. (2020). Membership. Retrieved from https://assistancedogsinternational.org/members/membership/ 
Audrestch, H. M., Whelan, C. T., Grice, D., Asher, L., England, G. C. W., \& Freeman, S. L. (2015). Recognizing the value of assistance dogs in society. Disability and Health Journal, (4), 469-474. https://doi.org/10.1016/j.dhjo.2015.07.001

Bibbo, J., Rodriguez, K. E., \& O’Haire, M. E. (2019). Impact of service dogs on family members' psychosocial functioning. American Journal of Occupational Therapy, 73(3), 1-11. https://doi.org/10.5014/ajot.2019.031690

Camp, MM. (2001). The use of service dogs as an adaptive strategy: A qualitative study. American Journal of Occupational Therapy, 55(5), 509-517. https://doi.org/10.5014/ajot.55.5.509

Canine Support Teams Inc. (n.d.). Service Dogs. Retrieved from http://www.caninesupportteams.org/service-dogs/

Champagne, A., Gagnon, D. H., \& Vincent, C. (2016). Comparison of cardiorespiratory demand and rate of perceived exertion during propulsion in a natural environment with and without the use of a mobility assistance dog in manual wheelchair users. American Journal of Physical Medicine \& Rehabilitation, 95(9), 685-691.

Chiron Health. (2019). Definitive guide to telemedicine. Retrieved from https: //chiron health.com/definitive-guide-to-telemedicine/telemedicine-resources/associationsagencies/

Cook, A. M. \& Polgar, J. M. (2015). Assistive technologies: Principles and practice ( $4^{\text {th }}$ ed.). St. Louis, MO: Elsevier.

Crowe, T. K., \& Nguyen, M. T. (2018). How service dogs enhance veterans' occupational performance in the home: A qualitative perspective. Open Journal of Occupational Therapy (OJOT), 6(3), 1-15. 
Crowe, T. K., Perea-Burns, S., Sedillo, J. S., Hendrix, I. C., Winkle, M., \& Deitz, J. (2014). Effects of partnerships between people with mobility challenges and service dogs. American Journal of Occupational Therapy, 68(2), 194-202.

Disabled Resource Services. (2019). 10 things you didn’t know about service dogs. Retrieved from https://disabledresourceservices.org/10-things-you-didnt-knowabout-service-dogs/

Dogs for Good. (2020). Successor dogs. Retrieved from https://www.dogsforgood .org/our-dogs/from-pup-to-partner/retirement/successor-dogs/

Dunn, W. (2008). Ecology of human performance. In M.B. Cole and R. Tufano (Eds.), Applied theories in occupational therapy: A practical approach (pp. 117-124). Thorofare, NJ: Slack, Inc.

Dunn, W., Brown, C., \& McGuigan, A. (1994). The ecology of human performance: A framework for considering the effect of context. American Journal of Occupational Therapy, 48(7), 595-607. https://doi.org/10.5014/ajot.48.7.595

Elliott, D., \& Hogle, P. S. (2013). Access rights and access wrongs: Ethical issues and ethical solutions for service dog use. International Journal of Applied Philosophy, 27(1), 1-14. https://doi.org/10.5840/ijap20132716

Fairman, S. K. \& Huebner, R. A. (2001). Service dogs: a compensatory resource to improve function. Occupational Therapy in Health Care, 14(1), 41-52. https://doi.org/10.1080/J003v13n02_03

Gately, M. E., Trudeau, S. A., \& Moo, L. R. (2020). Feasibility of telehealth-delivered home safety evaluations for caregivers of clients with dementia. OTJR: Occupation, Participation \& Health, 40(1), 42-49. 
https://doi.org/10.1177/1539449219859935

Hicks, J. R., \& Weisman, C. J. (2015). Work or play? An exploration of the relationships between people and their service dogs in leisure activities. Journal of Leisure Research, (2), 243. https://doi.org/10.1080/00222216.2015.11950359

Hubert, G., Tousignant, M., Routhier, F., Corriveau, H., \& Champagne, N. (2013). Effect of service dogs on manual wheelchair users with spinal cord injury: A pilot study. Journal of Rehabilitation Research \& Development, 50(3), 341-350. https://doi.org/10.1682/jrrd.2011.07.0124

Lloyd, J. K., Budge, C., Grow, S. L., \& Stafford, K. (2016). An investigation of the complexities of successful and unsuccessful guide dog matching and partnerships. Frontiers in Veterinary Science, 3, 1-15. https://doi.org/10.3389/fvets.2016.00114

Martin-Lemoyne, V., Gagnon, D. H., Routhier, F., Poissant, L., Tousignant, M., Corriveau, H., \& Vincent, C. (2016). To what extent can the use of a mobility assistance dog reduce upper limb efforts when manual wheelchair users ascend a ramp? Journal of Applied Biomechanics, 32(2), 186-195.

Mudge, S., Rewi, D., \& Channon, A. (2017). Identifying an outcome measure to assess the impact of mobility dogs. Disability \& Rehabilitation: Assistive Technology, 12(1), 73-83. https://doi.org/10.3109/17483107.2015.1079267

Ng, P.W., James M.A., \& McDonald, C. (2000). Service dogs for disabled children: Effects on level of independence and quality of life. Topics in Spinal Cord Injury Rehabilitation, 6, 96-104.

Pierce, L. (2018). Understanding and working with service dog handlers. American 
Counseling Association. Retrieved April 6, 2020, from https://ct.counseling.org /2018/10/understanding-and-working-with-service-dog-handlers/

Reisen, J. (2019, July 31). Service dogs, emotional support dogs, therapy dogs: What's the difference? [Blog post]. Retrieved from https://www.akc.org/expertadvice/lifestyle/service-emotional-support-ptsd-therapy-difference/

Rintala, D. H., Matamoros, R., \& Seitz, L. L. (2008). Effects of assistance dogs on persons with mobility or hearing impairments: A pilot study. Journal of Rehabilitation Research \& Development, 45(4), 489-503. https://doi.org/10.1682/jrrd.2007.06.0094

Service Dog Certifications. (2017). How much does it cost to train a service dog. Retrieved from https://www.servicedogcertifications.org/how-much-does-it-costto-train-a-service-dog/

Schell, B., Gillen, G., \& Scaffa, M. (2014). Willard \& Spackman's occupational therapy (12 ${ }^{\text {th }}$ ed.). Philadelphia, PA: Lippincott Williams \& Wilkins.

University of Buffalo. (2017). Home safety self assessment tool (HSSAT) v.5 [PDF file].

Retrieved from https://sphhp.buffalo.edu/content/sphhp/rehabilitationscience/research-and-facilities/funded-research/aging/home-safety-selfassessment-tool/_jcr_content/par/download_526197706/file.res/HSSAT-v.5-1-1217.pdf

U.S. Department of Justice. (2015). Service animals. Retrieved from https://www.ada.gov/service_animals_2010.htm

Vincent, C., Gagnon, D. H., Routhier, F., Dumont, F., Poissant, L., Corriveau, H., \& Tousignant, M. (2015). Service dogs for people with spinal cord injury: Outcomes 
regarding functional mobility and important occupations. Studies in Health Technology \& Informatics, 217, 847-851.

Vincent, C., Gagnon, D., Routhier, F., Leblond, J., Boucher, P., Blanchet, M., \& MartinLemoyne, V. (2015). Service dogs in the province of Quebec: Sociodemographic profile of users and the dogs' impact on functional ability. Disability Rehabilitation: Assistive Technology, 10(2), 132-140.

Vincent, C., Poissant, L., Gagnon, D. H., \& Corriveau, H. (2016). Consensus building for the development of guidelines for recommending mobility service dogs for people with motor impairments. Technology \& Disability, 28(3), 67-77.

Walther, S., Yamamoto, M., Thigpen, A. P., Garcia, A., Willits, N. H., \& Hart, L. A. (2017). Assistance dogs: Historic patterns and roles of dogs placed by ADI or IGDF accredited facilities and by non-accredited U.S. facilities. Frontiers in Veterinary Ccience, 4, 1-14. doi:10.3389/fvets.2017.00001

Winkle, M., Crowe, T. K., \& Hendrix, I. (2012). Service dogs and people with physical disabilities partnerships: A systematic review. Occupational Therapy International, 19(1), 54-66. https://doi.org/10.1002/oti.323

York, S., \& Whiteside, H. (2018). Exploring social (non-working) behavior in guide dogs from the perspective of guide dog owners. Anthrozoos, 31(5), 525-536. https://doi.org/10.1080/08927936.2018.1505259

Zapf, S. A., \& Rough, R. B. (2002). The development of an instrument to match individuals with disabilities and service animals. Disability \& Rehabilitation, 24(1-3), 47-58. https://doi.org/10.1080/09638280110066316 


\section{Appendix A}

\section{Sample Interview Questions}

Before obtaining assistance dog for Guide Dogs for the Blind

\begin{tabular}{|c|c|}
\hline \multicolumn{2}{|l|}{ Name } \\
\hline Date of Interview & \\
\hline $\begin{array}{l}\text { Name of Assistance Dog } \\
\text { Program }\end{array}$ & Guide Dogs for the Blind \\
\hline Disability/limitations? & \\
\hline $\begin{array}{l}\text { How long was your wait to } \\
\text { be accepted after all the } \\
\text { paperwork was submitted? } \\
\text { Was there anything you } \\
\text { found difficult in the } \\
\text { application process? }\end{array}$ & \\
\hline $\begin{array}{l}\text { Has your condition changed } \\
\text { since you first applied? }\end{array}$ & \\
\hline $\begin{array}{l}\text { Is this your first assistance } \\
\text { dog? If no, then why? }\end{array}$ & \\
\hline $\begin{array}{l}\text { Can you tell me about your } \\
\text { daily routine? This can } \\
\text { include self-care, } \\
\text { productivity, and leisure. }\end{array}$ & $\begin{array}{l}\text { Self-care (functional mobility, community management): } \\
\text { Productivity (paid or unpaid work), household management: } \\
\text { Leisure (quiet recreation, active recreation, socialization): }\end{array}$ \\
\hline $\begin{array}{l}\text { How do you think your } \\
\text { routine will change with an } \\
\text { assistance dog? }\end{array}$ & \\
\hline
\end{tabular}




\begin{tabular}{|c|c|}
\hline $\begin{array}{l}\text { In which occupations or } \\
\text { tasks will the assistance dog } \\
\text { aid in? }\end{array}$ & Mobility \\
\hline $\begin{array}{l}\text { Is your home environment } \\
\text { prepared for an assistance } \\
\text { dog (i.e. adequate space to } \\
\text { walk, sleeping area for the } \\
\text { dog, exercise area, potty } \\
\text { area)? If renting-how will } \\
\text { you prepare your landlord/ } \\
\text { neighbors? }\end{array}$ & \\
\hline $\begin{array}{l}\text { What environment changes } \\
\text { do you plan on making } \\
\text { before the assistance dog } \\
\text { arrives? }\end{array}$ & \\
\hline $\begin{array}{l}\text { Do you currently use } \\
\text { assistive devices? }\end{array}$ & \\
\hline $\begin{array}{l}\text { If you live with others, how } \\
\text { do think an assistance dog } \\
\text { will impact the home } \\
\text { dynamic? Other pets? }\end{array}$ & \\
\hline $\begin{array}{l}\text { Have you explored different } \\
\text { resources before deciding to } \\
\text { obtain an assistance dog? }\end{array}$ & \\
\hline $\begin{array}{l}\text { What do you hope to get out } \\
\text { of the } 2 \text {-week service } \\
\text { training? }\end{array}$ & \\
\hline $\begin{array}{l}\text { What material have you } \\
\text { received prior to the two- } \\
\text { week service training? }\end{array}$ & \\
\hline $\begin{array}{l}\text { Is there additional } \\
\text { information you would have } \\
\text { liked to receive that you } \\
\text { would find helpful? }\end{array}$ & \\
\hline Additional comments & \\
\hline
\end{tabular}


During two-week service training for Canine Companions for Independence

\begin{tabular}{|c|c|}
\hline Name & \\
\hline Date of Interview & \\
\hline $\begin{array}{l}\text { Name of Assistance Dog } \\
\text { Program }\end{array}$ & Canine Companions for Independence \\
\hline Diagnosis & \\
\hline $\begin{array}{l}\text { What was your wait time to } \\
\text { get to team training? }\end{array}$ & \\
\hline $\begin{array}{l}\text { Is this your first assistance } \\
\text { dog? If no, then why? }\end{array}$ & \\
\hline $\begin{array}{l}\text { What was the cost to obtain } \\
\text { your current assistance dog? }\end{array}$ & $\$ 0$ \\
\hline $\begin{array}{l}\text { Did you need any financial } \\
\text { assistance during this } \\
\text { training? This can include } \\
\text { transportation to/from } \\
\text { campus, associated travel } \\
\text { costs, or needing assistance } \\
\text { to maintaining dog after they } \\
\text { graduate (vet care, food, } \\
\text { grooming, supplies, etc.) }\end{array}$ & \\
\hline $\begin{array}{l}\text { Were you aware of the costs } \\
\text { of obtaining/maintaining a } \\
\text { dog? First dog? }\end{array}$ & \\
\hline $\begin{array}{l}\text { In which occupations or } \\
\text { tasks will the assistance dog } \\
\text { aid in? }\end{array}$ & \\
\hline $\begin{array}{l}\text { Can you tell me about your } \\
\text { daily routine? This can } \\
\text { include self-care, } \\
\text { productivity, and leisure. }\end{array}$ & $\begin{array}{l}\text { Self-care (personal care, functional mobility, community } \\
\text { management: } \\
\text { Productivity (paid or unpaid work), household management: } \\
\text { Retired } \\
\text { Leisure (quiet recreation, active recreation, socialization): }\end{array}$ \\
\hline
\end{tabular}




\begin{tabular}{|c|c|}
\hline $\begin{array}{l}\text { Do you think your home } \\
\text { environment is prepared for } \\
\text { an assistance dog (i.e. } \\
\text { adequate space to walk, } \\
\text { sleeping area for the dog, } \\
\text { tugs for cabinets or fridge, } \\
\text { exercise area, potty area)? If } \\
\text { renting, will there be a } \\
\text { problem with your } \\
\text { landlord/neighbors? First } \\
\text { dog? }\end{array}$ & \\
\hline $\begin{array}{l}\text { Would you have found it } \\
\text { beneficial if someone had } \\
\text { come to evaluate your home } \\
\text { before the assistance dog } \\
\text { arrived? Adding tugs, } \\
\text { blocking cords, designating a } \\
\text { sleep area, possibly } \\
\text { rearranging furniture? }\end{array}$ & \\
\hline $\begin{array}{l}\text { Do you currently have } \\
\text { assistive devices? }\end{array}$ & \\
\hline $\begin{array}{l}\text { Are you being taught how to } \\
\text { work with your assistance } \\
\text { dog and assistive device } \\
\text { together? }\end{array}$ & \\
\hline $\begin{array}{l}\text { If you live with others, how } \\
\text { do you think the assistance } \\
\text { dog will impact your home } \\
\text { dynamic? Other pets? }\end{array}$ & \\
\hline $\begin{array}{l}\text { Are any responsibilities new } \\
\text { to you that you were not } \\
\text { aware of during this } \\
\text { training? }\end{array}$ & \\
\hline $\begin{array}{l}\text { Do you feel like a bond has } \\
\text { been created between you } \\
\text { and your dog? }\end{array}$ & \\
\hline $\begin{array}{l}\text { What follow up support is } \\
\text { being offered by your service } \\
\text { dog agency that you are } \\
\text { aware of? }\end{array}$ & \\
\hline
\end{tabular}


Are you being trained to continue to reinforce your dog's skills so that they stay sharp after you take your dog home?

How confident do you feel about teaching your dog a new commands? 1-10

Any additional thoughts or obstacles you may have experienced during this training?

During two-week service training for Guide Dogs for the Blind

\begin{tabular}{|l|l|}
\hline Name & \\
\hline Date of Interview & Guide Dogs for the Blind \\
\hline $\begin{array}{l}\text { Name of Assistance Dog } \\
\text { Program }\end{array}$ & \\
\hline $\begin{array}{l}\text { Disability/limitations } \\
\text { Was there anything you } \\
\text { application process? }\end{array}$ & \\
$\begin{array}{l}\text { Has your condition changed } \\
\text { since you first applied? }\end{array}$ & \\
Harness pain? & \\
\hline $\begin{array}{l}\text { What was your wait time to } \\
\text { get to team training after the } \\
\text { personal interview? }\end{array}$ & \\
\hline $\begin{array}{l}\text { Is this your first assistance } \\
\text { dog? If no, then why? }\end{array}$ & \\
\hline What was the cost to obtain & $\mathbf{\$ 0}$ \\
\hline
\end{tabular}




\begin{tabular}{|c|c|}
\hline your current assistance dog? & \\
\hline $\begin{array}{l}\text { Did you need any financial } \\
\text { assistance during this } \\
\text { training? This can include } \\
\text { transporation to/from } \\
\text { campus, associated travel } \\
\text { costs, or needing assistance } \\
\text { to maintaining dog after they } \\
\text { graduate (vet care, food, } \\
\text { grooming, supplies, etc.) }\end{array}$ & $\begin{array}{l}\text { GDB pays for transportation to and from. We provide } \\
\text { grooming supplies, have a veterinary financial assistance } \\
\text { program for those who need it, and expect all clients to be } \\
\text { able to provide food and the basics for their guide dog to } \\
\text { the estimated amound of } \$ 70 / \mathrm{month} \text {. }\end{array}$ \\
\hline \multicolumn{2}{|l|}{$\begin{array}{l}\text { Were you aware of the costs } \\
\text { of obtaining/maintaining a } \\
\text { dog? }\end{array}$} \\
\hline $\begin{array}{l}\text { In which occupations or } \\
\text { tasks will the assistance dog } \\
\text { aid in? }\end{array}$ & Mobility \\
\hline $\begin{array}{l}\text { Can you tell me about your } \\
\text { daily routine? This can } \\
\text { include self-care, } \\
\text { productivity, and leisure. }\end{array}$ & $\begin{array}{l}\text { Self-care (functional mobility, community management): } \\
\text { Productivity (paid or unpaid work), academics, household } \\
\text { management: } \\
\text { Leisure (quiet recreation, active recreation, socialization): } \\
\text { Walks 1-2 miles a day depending on the weather, likes } \\
\text { recreation walks in the summer about } 3 \text { miles (2-3 times a } \\
\text { week), swims } 80 \text { laps several times a week }\end{array}$ \\
\hline $\begin{array}{l}\text { What envrionmental changes } \\
\text { will you make to your home } \\
\text { according to the personal } \\
\text { interview? }\end{array}$ & \\
\hline $\begin{array}{l}\text { Do you currently have } \\
\text { assistive devices? }\end{array}$ & \\
\hline $\begin{array}{l}\text { Are you being taught how to } \\
\text { work with your assistance } \\
\text { dog and assistive device } \\
\text { together? }\end{array}$ & \\
\hline If you live with others, how & \\
\hline
\end{tabular}




\begin{tabular}{|c|c|}
\hline $\begin{array}{l}\text { do you think the assistance } \\
\text { dog will impact your home } \\
\text { dynamic? Other pets? }\end{array}$ & \\
\hline $\begin{array}{l}\text { Are any responsibilities new } \\
\text { to you that you were not } \\
\text { aware of during this } \\
\text { training? }\end{array}$ & \\
\hline $\begin{array}{l}\text { Do you feel like a bond has } \\
\text { been created between you } \\
\text { and your dog? }\end{array}$ & \\
\hline $\begin{array}{l}\text { What follow up support is } \\
\text { being offered by your service } \\
\text { dog agency? }\end{array}$ & $\begin{array}{l}\text { Standard is a telephone at } 2 \text { weeks and } 10 \text { weeks post } \\
\text { graduation, and in person visit the first and second year of } \\
\text { a first time guide dog user, an in person visit the first year } \\
\text { for a retrain client, annual telephonic if not in person, } \\
\text { followed by a return to in person visits when the dog turns. } \\
\text { Telephonic support avaiable during business hours-results } \\
\text { of call could trigger an emergent in person visit within two } \\
\text { weeks, depending on nature of problems. }\end{array}$ \\
\hline $\begin{array}{l}\text { Are you being trained to } \\
\text { continue to reinforce your } \\
\text { dog's skills so that they stay } \\
\text { sharp after you take your dog } \\
\text { home? }\end{array}$ & \\
\hline $\begin{array}{l}\text { Additional comments or } \\
\text { obstacles you would like to } \\
\text { discuss? }\end{array}$ & \\
\hline
\end{tabular}

After two-week service training for Canine Companions for Independence

\begin{tabular}{|l|l|}
\hline Name & \\
\hline Date of Interview & \\
\hline $\begin{array}{l}\text { Name of Assistance Dog } \\
\text { Program }\end{array}$ & Canine Companions for Independence \\
\hline $\begin{array}{l}\text { Is this your first assistance } \\
\text { dog? If no, then why? }\end{array}$ & \\
\hline
\end{tabular}




\begin{tabular}{|c|c|}
\hline $\begin{array}{l}\text { How long have you owned } \\
\text { your assistance dog? }\end{array}$ & \\
\hline Disability & \\
\hline $\begin{array}{l}\text { What was the cost to obtain } \\
\text { your current assistance dog? }\end{array}$ & $\$ 0$ \\
\hline $\begin{array}{l}\text { How much do you pay to } \\
\text { maintain your dog monthly? }\end{array}$ & \\
\hline $\begin{array}{l}\text { Were you aware of the costs } \\
\text { of obtaining/maintaining a } \\
\text { dog? }\end{array}$ & \\
\hline $\begin{array}{l}\text { Can you tell me about your } \\
\text { daily routine since you have } \\
\text { gained an assistance dog? } \\
\text { This can include self-care, } \\
\text { productivity, and leisure. }\end{array}$ & $\begin{array}{l}\text { Self-care (personal care, functional mobility, community } \\
\text { management: } \\
\text { Productivity (paid or unpaid work), household management: } \\
\text { Leisure (quiet recreation, active recreation, socialization): }\end{array}$ \\
\hline $\begin{array}{l}\text { In which occupations or tasks } \\
\text { will the assistance dog aid in? }\end{array}$ & \\
\hline $\begin{array}{l}\text { Is there a task you have not } \\
\text { thought about that the dog } \\
\text { assisted you with? }\end{array}$ & \\
\hline $\begin{array}{l}\text { Did you find the } 2 \text {-week } \\
\text { service training sufficient? If } \\
\text { no, then why? }\end{array}$ & \\
\hline $\begin{array}{l}\text { Is there something you wish } \\
\text { the training included? }\end{array}$ & \\
\hline $\begin{array}{l}\text { Was your home environment } \\
\text { prepared for an assistance dog } \\
\text { (i.e. adequate space to walk, } \\
\text { sleeping area for the dog, tugs } \\
\text { for cabinets or fridge, exercise } \\
\text { are for dog, potty area)? If } \\
\text { renting-was there a problem } \\
\text { your landlord/neighbors? }\end{array}$ & \\
\hline
\end{tabular}




\begin{tabular}{|c|c|}
\hline $\begin{array}{l}\text { Would you have found it } \\
\text { beneficial if someone had } \\
\text { come to evaluate your home } \\
\text { before the assistance dog } \\
\text { arrived? }\end{array}$ & \\
\hline $\begin{array}{l}\text { Do you currently have } \\
\text { assistive devices? }\end{array}$ & \\
\hline $\begin{array}{l}\text { Were you taught how to work } \\
\text { with your assistance dog and } \\
\text { assistive device together? }\end{array}$ & \\
\hline $\begin{array}{l}\text { Was the harness for your } \\
\text { assistance dog adequate or did } \\
\text { it need to be adjusted? }\end{array}$ & \\
\hline $\begin{array}{l}\text { Do you feel like a bond has } \\
\text { been created between you and } \\
\text { your dog? }\end{array}$ & \\
\hline $\begin{array}{l}\text { If you live with others, how } \\
\text { has the assistance dog } \\
\text { impacted the home dynamic? } \\
\text { Other pets? }\end{array}$ & \\
\hline $\begin{array}{l}\text { Are any responsibilities new } \\
\text { to you that you were not } \\
\text { aware of? }\end{array}$ & \\
\hline $\begin{array}{l}\text { Are you being trained to } \\
\text { continue to reinforce your } \\
\text { dogs skills so that they stay } \\
\text { sharp after you take your dog } \\
\text { home? }\end{array}$ & \\
\hline Additonal comments: & \\
\hline
\end{tabular}

After two-week service training for Canine Support Teams

\begin{tabular}{|l|l|}
\hline Name & \\
\hline Date of Interview & \\
\hline
\end{tabular}




\begin{tabular}{|c|c|}
\hline $\begin{array}{l}\text { Name of Assistance Dog } \\
\text { Program }\end{array}$ & Canine Support Teams \\
\hline $\begin{array}{l}\text { Is this your first assistance } \\
\text { dog? If no, then why? }\end{array}$ & \\
\hline $\begin{array}{l}\text { How long have you owned } \\
\text { your assistance dog? }\end{array}$ & \\
\hline Diagnosis & \\
\hline $\begin{array}{l}\text { What was the cost to obtain } \\
\text { your current assistance dog? }\end{array}$ & $\$ 6,500$ \\
\hline $\begin{array}{l}\text { Did you have any assistance } \\
\text { to pay for an assistance dog? }\end{array}$ & \\
\hline $\begin{array}{l}\text { How much do you pay to } \\
\text { maintain your dog monthly? }\end{array}$ & \\
\hline $\begin{array}{l}\text { Were you aware of the costs } \\
\text { of obtaining/maintaining a } \\
\text { dog? }\end{array}$ & \\
\hline $\begin{array}{l}\text { Can you tell me about your } \\
\text { daily routine since you have } \\
\text { gained an assistance dog? } \\
\text { This can include self-care, } \\
\text { productivity, and leisure. }\end{array}$ & $\begin{array}{l}\text { Self-care (personal care, functional mobility, community } \\
\text { management: } \\
\text { Productivity (paid or unpaid work), household management: } \\
\text { Leisure (quiet recreation, active recreation, socialization): }\end{array}$ \\
\hline $\begin{array}{l}\text { In which occupations or tasks } \\
\text { will the assistance dog aid in? }\end{array}$ & \\
\hline $\begin{array}{l}\text { Is there a task you have not } \\
\text { thought about that the dog } \\
\text { assisted you with? }\end{array}$ & \\
\hline $\begin{array}{l}\text { Did you find the } 2 \text {-week } \\
\text { service training sufficient? If } \\
\text { no, then why? }\end{array}$ & \\
\hline $\begin{array}{l}\text { Is there something you wish } \\
\text { the training included? }\end{array}$ & \\
\hline
\end{tabular}


Was your home environment

prepared for an assistance dog (i.e. adequate space to walk, sleeping area for the dog, tugs for cabinets or fridge, exercise are for dog, potty area)? If renting-was there a problem your landlord/neighbors?

Would you have found it beneficial if someone had come to evaluate your home before the assistance dog arrived?

Do you currently have assistive devices?

Were you taught how to work with your assistance dog and assistive device together?

Was the harness for your assistance dog adequate or did it need to be adjusted?

Would you have found it beneficial if someone had come to evaluate your home before the assistance dog arrived?

Do you feel like a bond has been created between you and your $\operatorname{dog}$ ?

If you live with others, how has the assistance dog impacted the home dynamic? Other pets?

Are any responsibilities new to you that you were not aware of?

Are you being trained to 
continue to reinforce your dogs skills so that they stay sharp after you take your dog home?

Additonal comments?

After two-week service training for Guide Dogs for the Blind

\begin{tabular}{|c|c|}
\hline \multicolumn{2}{|l|}{ Name } \\
\hline Date of Interview & \\
\hline $\begin{array}{l}\text { Name of Assistance Dog } \\
\text { Program }\end{array}$ & Guide Dogs for the Bline \\
\hline $\begin{array}{l}\text { Is this your first assistance } \\
\text { dog? If no, then why? }\end{array}$ & \\
\hline $\begin{array}{l}\text { How long have you partnered } \\
\text { with your assistance dog? }\end{array}$ & \\
\hline Disability/limitations? & \\
\hline $\begin{array}{l}\text { Was the medical form done in } \\
\text { person? How long have you } \\
\text { known your physician? }\end{array}$ & \\
\hline $\begin{array}{l}\text { Do you have any sorness or } \\
\text { arm pain with your harness? }\end{array}$ & \\
\hline $\begin{array}{l}\text { How much do you pay to } \\
\text { maintain your dog monthly? }\end{array}$ & \\
\hline $\begin{array}{l}\text { Were you aware of the costs } \\
\text { of obtaining/maintaining a } \\
\text { dog? }\end{array}$ & \\
\hline $\begin{array}{l}\text { Can you tell me about your } \\
\text { daily routine since you have } \\
\text { gained an assistance dog? } \\
\text { This can include self-care, }\end{array}$ & $\begin{array}{l}\text { Self-care ( functional mobility, community management): } \\
\text { Productivity (paid or unpaid work), academics, household } \\
\text { management: }\end{array}$ \\
\hline
\end{tabular}




\begin{tabular}{|c|c|}
\hline productivity, and leisure. & Leisure (quiet recreation, active recreation, socialization): \\
\hline $\begin{array}{l}\text { In which occupations or tasks } \\
\text { does the assistance dog aid } \\
\text { in? }\end{array}$ & Mobility \\
\hline $\begin{array}{l}\text { Is there a task you have not } \\
\text { thought about that the dog } \\
\text { assisted you with? }\end{array}$ & \\
\hline $\begin{array}{l}\text { Did you find the } 2 \text {-week } \\
\text { service training sufficient? If } \\
\text { no, then why? }\end{array}$ & \\
\hline $\begin{array}{l}\text { Is there something you wish } \\
\text { the training included? }\end{array}$ & \\
\hline $\begin{array}{l}\text { What enironmental changes } \\
\text { did you make that were } \\
\text { unexpected when your } \\
\text { asssitance dog arrived? }\end{array}$ & \\
\hline $\begin{array}{l}\text { Do you currently have } \\
\text { assistive devices? }\end{array}$ & \\
\hline $\begin{array}{l}\text { Were you taught how to work } \\
\text { with your assistance dog and } \\
\text { assistive device together? }\end{array}$ & \\
\hline $\begin{array}{l}\text { Was the harness for your } \\
\text { assistance dog adjusted to } \\
\text { your comfort? Did it take tme } \\
\text { to adapt to holding it? }\end{array}$ & \\
\hline $\begin{array}{l}\text { Do you feel like a bond has } \\
\text { been created between you and } \\
\text { your dog? }\end{array}$ & \\
\hline $\begin{array}{l}\text { If you live with others, how } \\
\text { has the assistance dog } \\
\text { impacted the home dynamic? } \\
\text { Other pets? }\end{array}$ & \\
\hline
\end{tabular}




\begin{tabular}{|l|l|}
\hline $\begin{array}{l}\text { Are any responsibilities new } \\
\text { to you that you were not } \\
\text { aware of? }\end{array}$ & \\
\hline $\begin{array}{l}\text { Are you being trained to } \\
\text { continue to reinforce your } \\
\text { dogs skills so that they stay } \\
\text { sharp after you take your dog } \\
\text { home? }\end{array}$ & \\
\hline $\begin{array}{l}\text { Additional comments/ } \\
\text { obstacles? }\end{array}$ & \\
\hline
\end{tabular}




\section{Appendix B}

Qualitative Themes

Qualitative Themes

Themes Examples

Routines

"I'll have to watch less television and play more" (P4 GDB)

"I will have to wake up earlier before school for relieving and walking the dog" (P5 GDB)

"The hard part right now is that I don't have a consistent schedule, which makes it difficult for Ridder (guide dog), more than me" (P10 GDB)

Changing assistive devices, additional help from significant others, paid assistance, finalizing plans for adoption of first dog (P5 CCI; P1 CCI; P2 CCI; P4 CCI)

No longer wanted to incorporate a pet dog into their routine(P10 $\mathrm{CCI})$

He had to remind his children daily to put their toys, shoes, and food off the table to reduce unnecessary obedience training (P10 GDB)

Hardest thing for families to adjust to for the first six to twelve months was not being able to create a bond between the new assistance dog (P7 CCI; P10 GDB; P6 GDB; P2 CST)

Task Associated with New Occupations

"My family will help with picking up poop and my sister is a dog groomer, so she'll help with grooming. The kids will eventually learn more responsibilities as we go" (P7 CCI)

Significant others will help with exercise when needed (P1 CCI; P5 CCI; P8 CCI; P9 CCI; P13 CCI)

Felt jealously and sadness that they would not be part of their normal routine anymore (P6 CCI)

Physical Environment

Handlers with successor dogs were better prepared the second time around compared to first time user (P1 CCI; P2 CCI; P4 CCI; P5 CCI; 


\section{P6 GDB; P4 CST)}

Handlers, who use wheelchairs, mentioned that they did not have a strong desire to have a home evaluation because they had adapted their homes (P1 CCI; P2 CCI; P5 CCI; P8 CCI, P10 CCI)

"I would have been open to this idea, you don't know what you're getting into with the first dog." (P10 CCI)

"It's beneficial to understand your own limitations, since my disease is progressive" (P4 CCI)

"My whole world shook up, I had to make room for a large dog in the house, which meant big bed and big toys" (P4 CST)

Participant was not aware initially who was going to aid him in relieving his assistance dog and picking up the excrements within his community college campus (P8 CCI)

One participant, a mother, was open to a home evaluation because the nature of her home was unpredictable with three children (P7 CCI)

"They didn't walk around the house much, just saw the kitchen and living room" (P4 GDB)

“There's a lot I didn't realize, I'll get an actual kennel, make it feel more like home....get basic necessities like food bines, because I don't have that...if I move now, I have different considerations like a closed area for my dog to run in, since I live in a small apartment." (P7 GDB) 


\section{Appendix C}

\section{Learning Aids Cheat Sheet}

\begin{tabular}{|l|l|}
\hline Obedience Commands & Role-Specific \\
Bed- lies in dog bed & Back- walks backwards \\
Car-loads in vehicle & Fix- paw raises to untangle \\
Don't-verbal correction & Get- picks up item with mouth \\
Down-lies down & Give- lets go of item with mouth \\
Drop- release tug/toy from mouth & Hold- holds item in mouth \\
Heel-left side & Leash-retrieves leash \\
Here- return to handler & Out- crosses threshold and turns to face handler \\
Jump- four paws on raised surface & Push-push item with nose \\
Kennel-inside of a crate & Side-ride side \\
Lap-front legs on person's lap & Stand- stands on all four \\
Lets go-walks next to handler & Step- steps on wheelchair with front paws \\
Off- four paws to ground & Tug- tugs item with their mouth \\
Quiet- stops vocalizing & Up- front paws on raised surface \\
Shake- offers paw to greet & Visit- rests their head in lap \\
Sit- fear end on ground & \\
Stay-hold a command & \\
Under- lies down beneath object & \\
Wait- waits on one side of threshold & \\
\hline Service dog & Informal \\
Light-light switch up position & Dress- puts head through vest or collar \\
Pull-propel manual wheelchair & Fetch- retrieves and returns toy \\
Stop-stop pulling & Hurry-toilets in area indicated \\
Switch- light switch down position & Name- get attention \\
& OK- permitted to eat \\
& Release-move freely \\
& Roll- exposes belly \\
& Speak- bark \\
\hline
\end{tabular}




\section{Appendix D}

\section{Practice Schedule}

Practice schedule is an aid for first time handlers to be aware of how an assistance dog may impact their new routine. This schedule can prepare handlers how to adjust their schedule, get extra aid if needed, or predict unforeseen events.

*Schedule with assistance dog should include 2 feedings, at least 4 relieving times, and 1 exercise period.

\section{Daily Schedule}

\begin{tabular}{|c|c|c|c|}
\hline & Daily Routine & Daily Routine with assistance dog & $\sqrt{ }$ \\
\hline & & & \\
\hline $8: 00$ & wake up & wake up & \\
\hline $8: 30$ & take a shower & take the dog out and feed & \\
\hline $9: 00$ & eat breakfast & take a shower & \\
\hline $9: 30$ & get ready for the gym & take the dog for a walk & \\
\hline $10: 00$ & workout at the gym & workout at the gym & \\
\hline $10: 30$ & & & \\
\hline $11: 00$ & & & \\
\hline $11: 30$ & & & \\
\hline $12: 00$ & & & \\
\hline $12: 30$ & & & \\
\hline $1: 00$ & & & \\
\hline $1: 30$ & & & \\
\hline $2: 00$ & & & \\
\hline $2: 30$ & & & \\
\hline $3: 00$ & & & \\
\hline $3: 30$ & & & \\
\hline $4: 00$ & & & \\
\hline $4: 30$ & & & \\
\hline $5: 00$ & & & \\
\hline $5: 30$ & & & \\
\hline $6: 00$ & & & \\
\hline $6: 30$ & & & \\
\hline $7: 00$ & & & \\
\hline $7: 30$ & & & \\
\hline $8: 00$ & & & \\
\hline $8: 30$ & & & \\
\hline $9: 00$ & & & \\
\hline $9: 30$ & & & \\
\hline $10: 00$ & & & \\
\hline
\end{tabular}




\section{Appendix E}

\section{Task Changes}

This aid is here to address task changes within the support system. Handlers may not always be able to complete day-to-day responsibilities of an assistance dog due to unexpected occurrences. This aid can address who can takeover different responsibilities and when. By addressing task changes early on, handlers and their support system can create smooth transitions and adequate for care for their assistance dog.

Responsibility:

Reasons:

Who will takeover: Grooming pain/fatigue

Day/Time: Saturday morning

Responsibility: Feeding

Reasons:

Who will takeover: poor dexterity

Day/Time: daughter every night

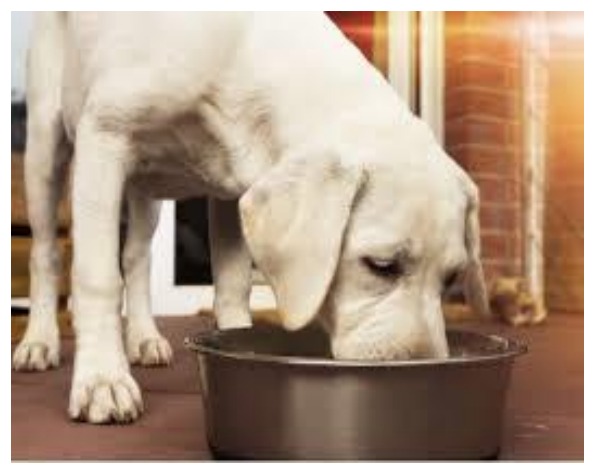

Responsibility:

Reasons:

Who will takeover:

Day/Time:

Responsibility:

Reasons:

Who will takeover:

Day/Time:

Responsibility:

Reasons:

Who will takeover:

Day/Time:

Responsibility:

Reasons:

Who will takeover:

Day/Time:
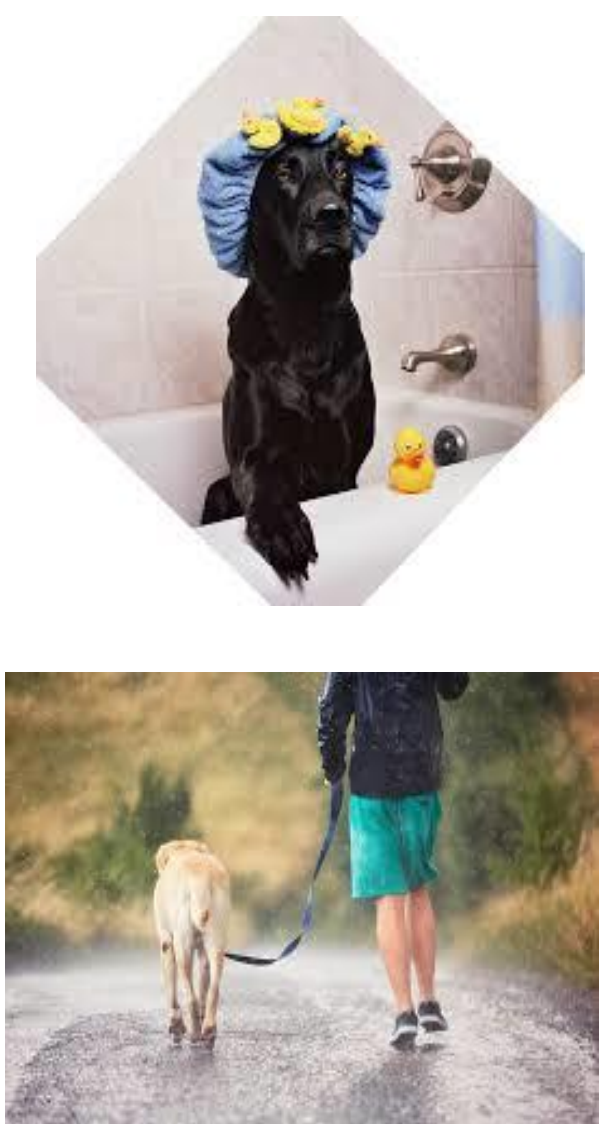
Appendix F

Modified Home Safety Assessment Checklist

\section{Home Safety Assessment Checklist for Assistance Dogs}

*Modified version of Home Safety Self Assessment Tool

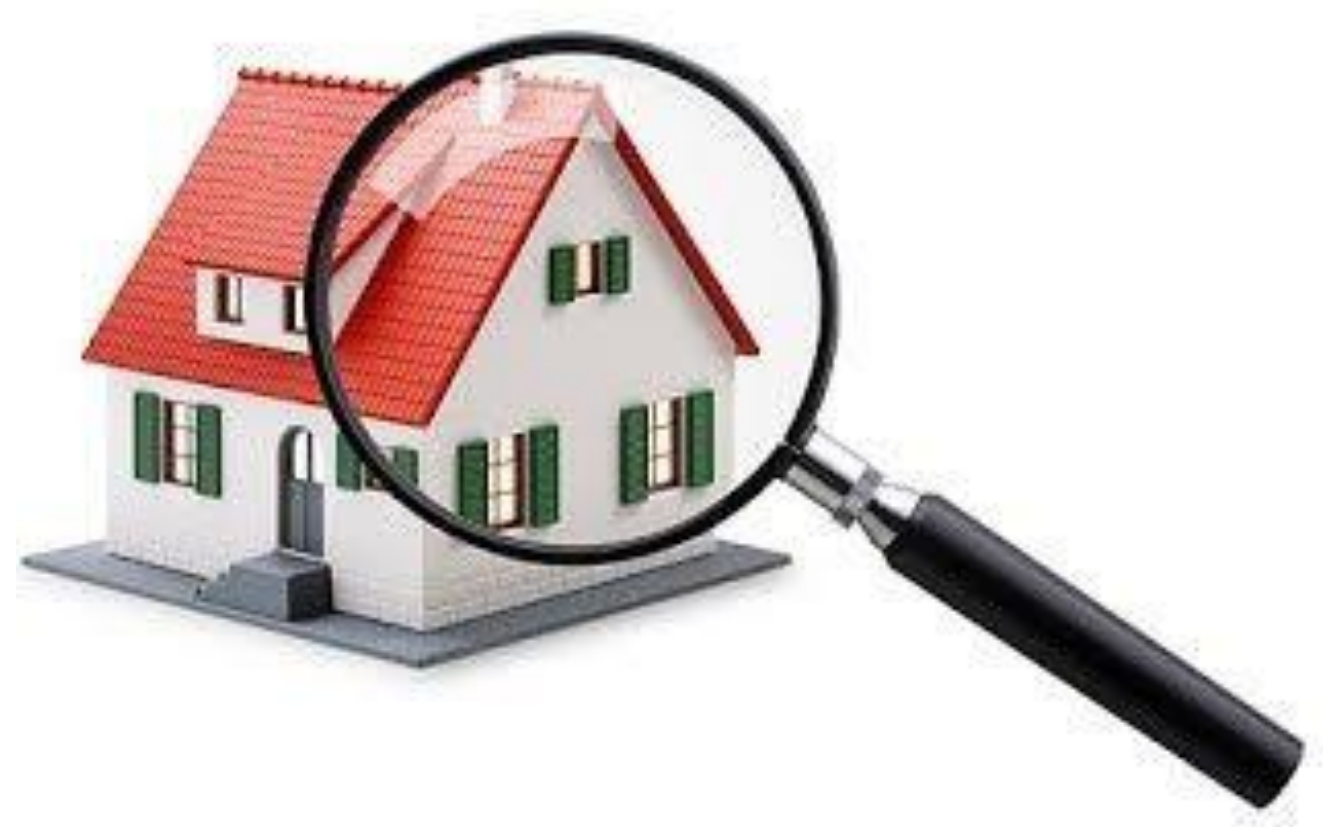




\section{Front Yard/Backyard}

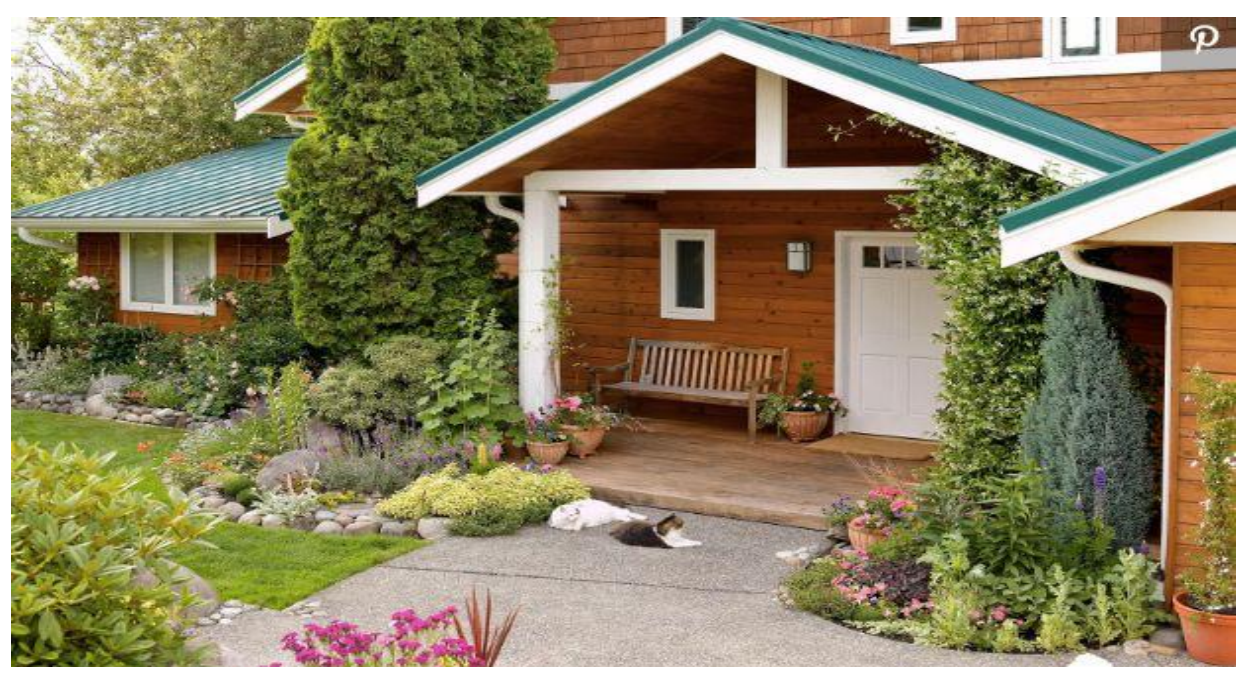

The list identifies all the potential home hazards for an assistance dog.
( Harmful plants
u Lose gardening tools
(1) Shed
( Ice or snow walkway
Q Outdoor decor
( Other animals
(] Area for releiving
( Other

Suggestions 


\section{Living/Family Room}

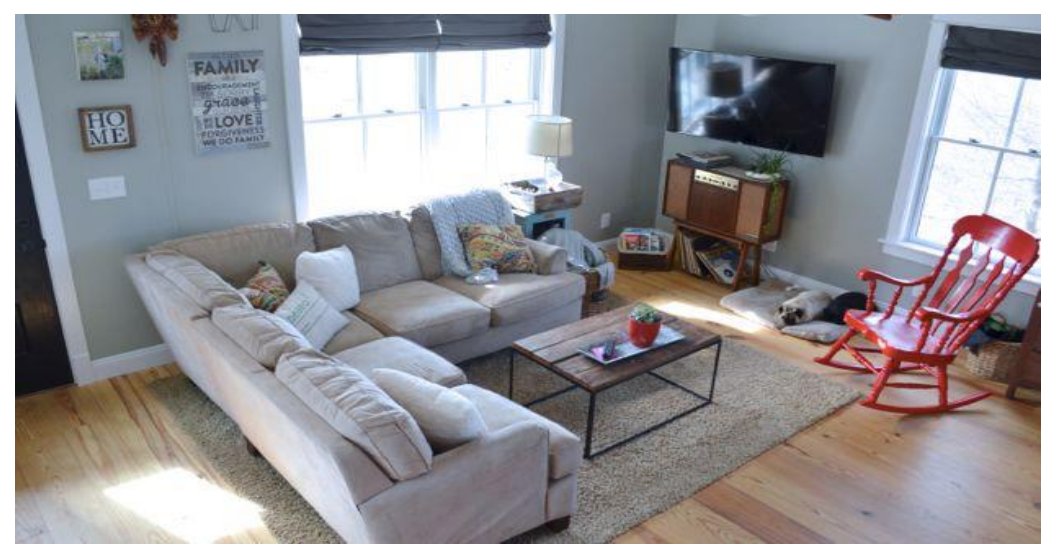

The list identifies all the potential home hazards for an assistance dog.
(- Cluttered table
(4) Loose electrical cords
Q Lamp cord
(4) Furniture arrangement
(] Open food
( Vases
ㄱ Fireplace
( Toys
4 Shoes
(1) Dog bed
(] Others

Suggestions 


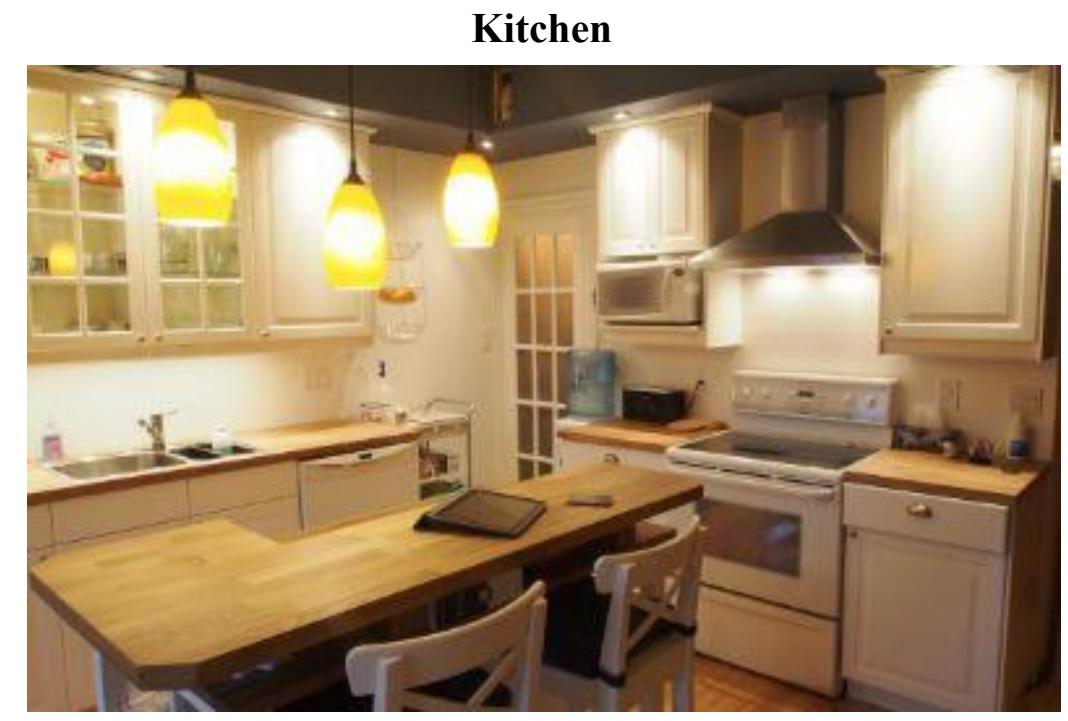

The list identifies all the potential home hazards for an assistance dog.

(]) Pantry

( Loose electrical cords

0 Counter clutter

(?) Dog feeding area

( Food bin for dog

( Open food containers or bags

( Jars

(- Cleaning products

0 Other

\section{Suggestions}




\section{Bedroom}

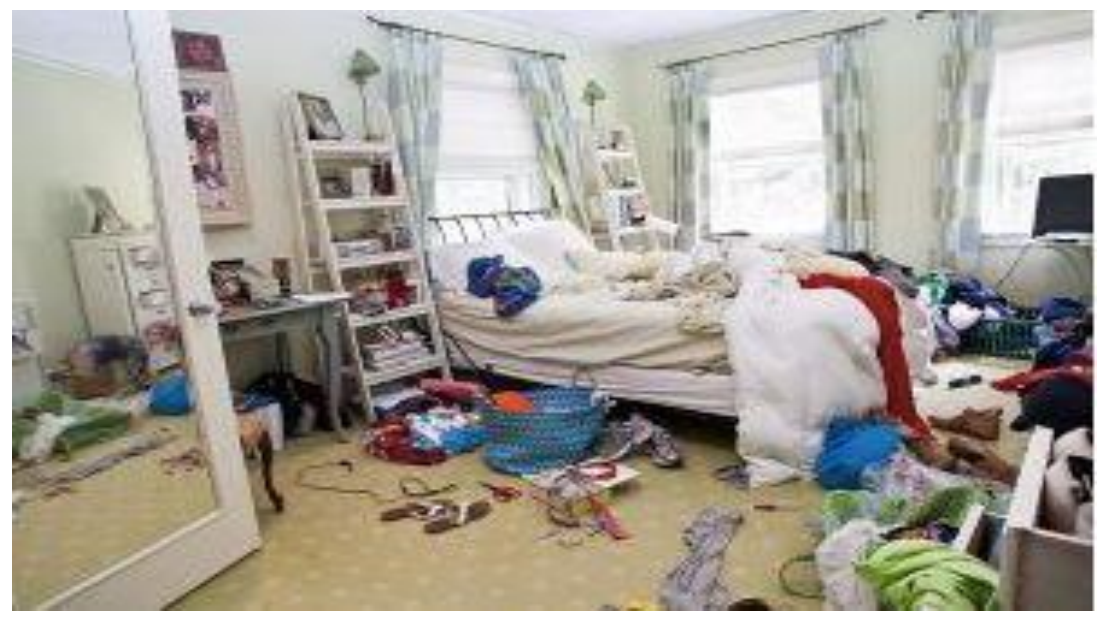

The list identifies all the potential home hazards for an assistance dog.
प Loose electrical cords
․ Toys
口 Cluttered walkway
[ Unstable items on shelves
(] Shoes
口 Items under the bed
口 Window
( Dog bed area
口 Other pets
口 Others

Suggestions 


\section{Bathroom}

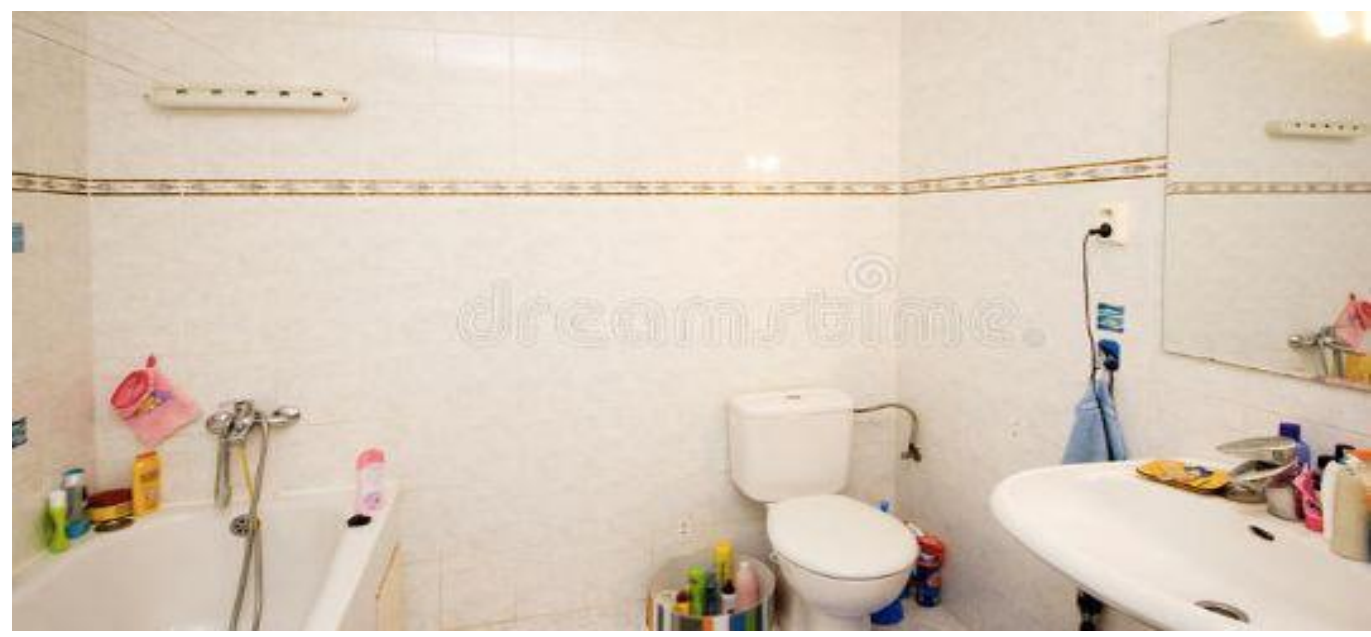

The list identifies all the potential home hazards for an assistance dog.

( Loose bath products

( Cluttered items on the counter

( Cleaning products

Q Children's bath toys

O Other animal food

( Other

\section{Suggestions}




\section{Garage/Basement}

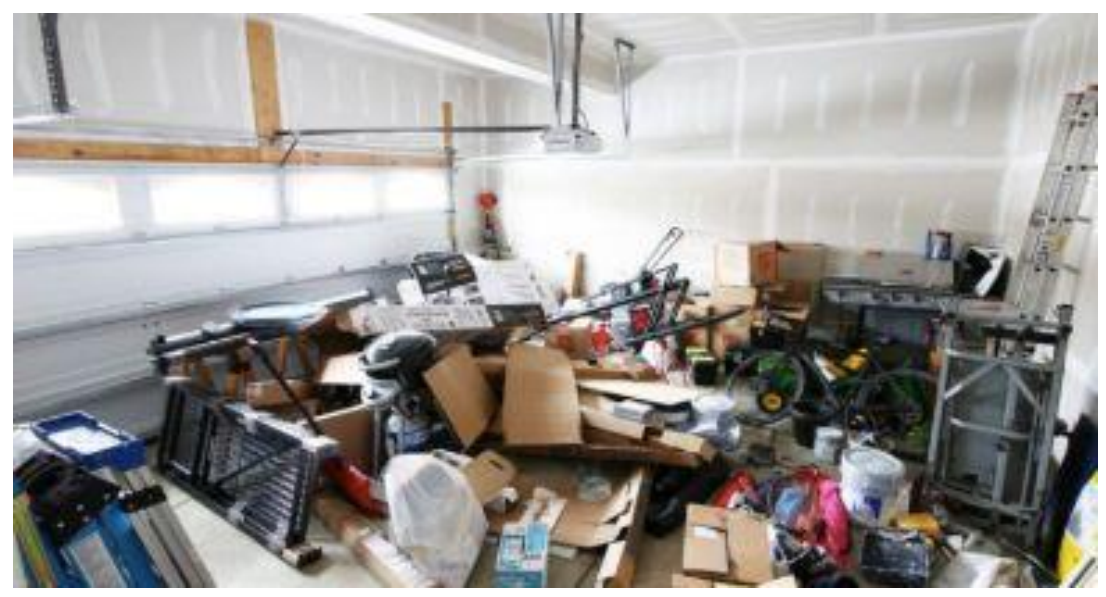

The list identifies all the potential home hazards for an assistance dog.

L Loose electrical cords

(] Cleaning products

( Clutter

T Toxic products

( Sharp items

U Unstable objects

(]) Dog food

( Food bins

( Other

Suggestions 
Additional Suggestions 


\section{Reference}

University of Buffalo. (2017). Home safety self assessment tool (HSSAT) v.5 [PDF file].

Retrieved from https://sphhp.buffalo.edu/content/sphhp/rehabilitation-

science/research-and-facilities/funded-research/aging/home-safety-self-

assessment-tool/_jcr_content/par/download_526197706/file.res/HSSAT-v.5-1-12-

17.pdf 


\section{Appendix G}

\section{Learning Activities}

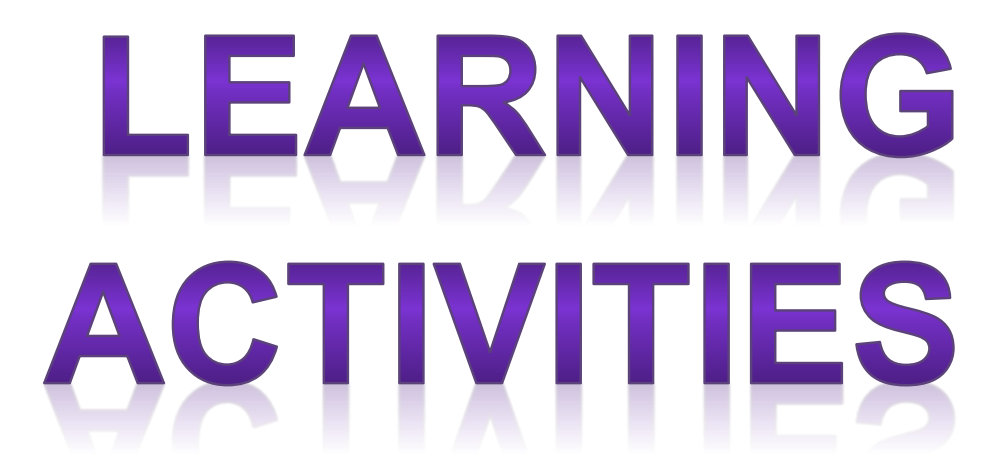

*The following learning activities are intended for instructors to experience how clients may be feeling on a day-to-day basis and how to better understand them. Activities were designed for instructors to better aid their client's learning needs. 


\title{
Pre-activity Questions
}

\section{Please get in a small group of 3-4 people while answering these questions.}

1) When learning a new activity, how do you like to be taught?

2) Give an example of a time you taught an activity to someone who had a different learning style from you (other than work)?

\begin{abstract}
Activity
Next, take the time to review each diagnosis. Under each diagnosis are learning activities. Have one person engage in one or two learning activities while guiding a dog around campus or downtown San Rafael for five to ten minutes. If possible, have a partner with you while doing a different learning activity. Try different activities from different diagnoses over the next week. It is encouraged that you carry on with your normal routine while engaging in these activities such as talking to staff on campus or taking a coffee break. At the end of the week, after completing activities, come together as a group and discuss your experiences with post-activity questions.
\end{abstract}

\section{*Activities best done on campus}

If foot brace cannot be found, wear one shoe will a slight heel while the other is flat. Amazon link is also provided below for low cost foot brace:

https://www.amazon.com/Alpha-Medical-Plantar-FascitisSplint/dp/B06WRP2Q7D/ref=sr 1 20?dchild=1\&keywords=foot+brace\&qid=15871685 $\underline{00 \& s r=8-20}$

\section{Post-activity Questions}

1) Was there anything you did not expect from this experience?

2) When engaging with others, how did you feel? Were you able to carry on a full conversation?

3) How do you think your teaching style will change after this experience?

4) Has this experience changed the way you will engage with future clients regarding their comorbidities?

5) How did this experience change the way you will interview clients? 


\section{Neuropathy}

Neuropathy or peripheral neuropathy is a result of damage to the nerves outside of the brain and spinal cord (peripheral nerves). Symptoms often cause weakness, numbness and pain, mainly in your hands and feet. It can also affect other areas of your body.

Your peripheral nervous system sends information from your brain and spinal cord (central nervous system) to the rest of your body. The peripheral nerves also send sensory information to the central nervous system.

Peripheral neuropathy can result from traumatic injuries, infections, metabolic problems, inherited causes and exposure to toxins. One of the most common causes is diabetes.

People with peripheral neuropathy generally describe the pain as stabbing, burning or tingling. Walking with a wobbly motion or even losing your balance can result from diabetic peripheral neuropathy. Other symptoms include muscle weakness and sensitivity to touch.

\section{Learning Activities}

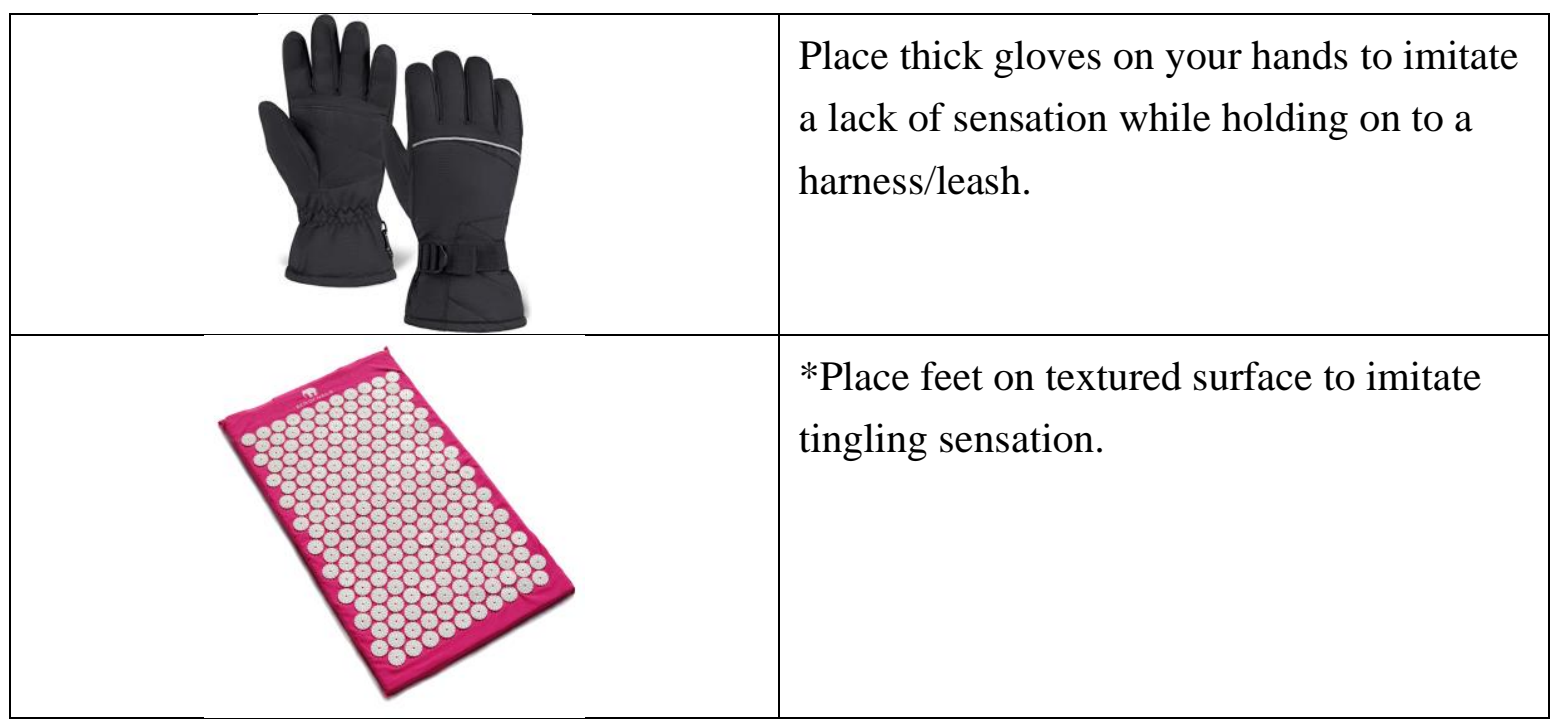




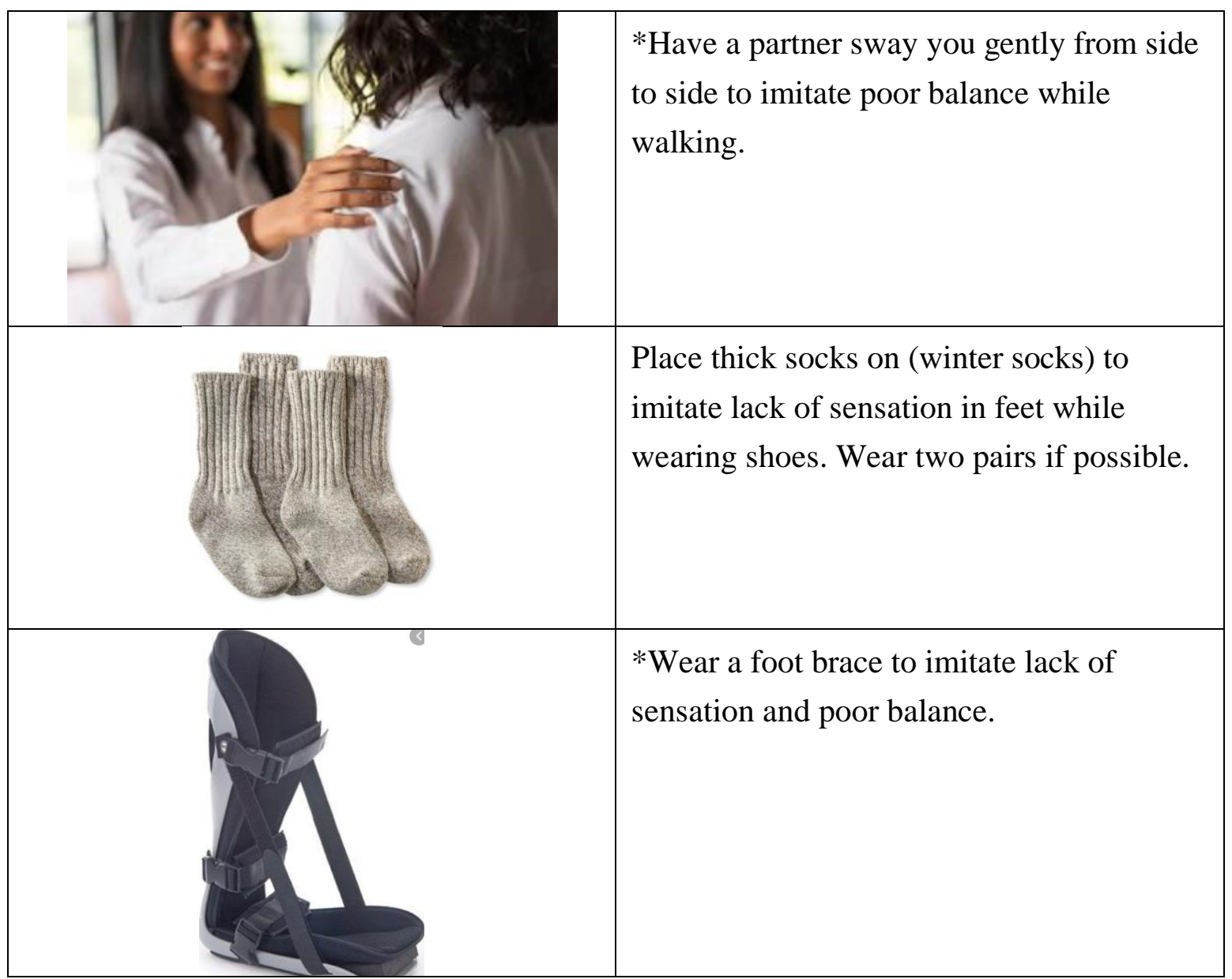

\section{References}

Healthline Media a Red Ventures Company. (2020). Symptoms of diabetic peripheral neuropathy. Retrieved from https://www.healthline.com/health/diabeticperipheral-neuropathy-symptoms

Mayo Foundation for Medical Education and Research. (2020). Peripheral neuropathy. Retrieved from https://www.mayoclinic.org/diseases-conditions/peripheralneuropathy/symptoms-causes/syc-20352061 


\section{Arthritis}

Arthritis is very common but is not well understood. Actually, "arthritis" is not a single disease; it is an informal way of referring to joint pain or joint disease. There are more than 100 types of arthritis and related conditions. People of all ages, sexes and races can and do have arthritis, and it is the leading cause of disability in America. More than 50 million adults and 300,000 children have some type of arthritis. It is most common among women and occurs more frequently as

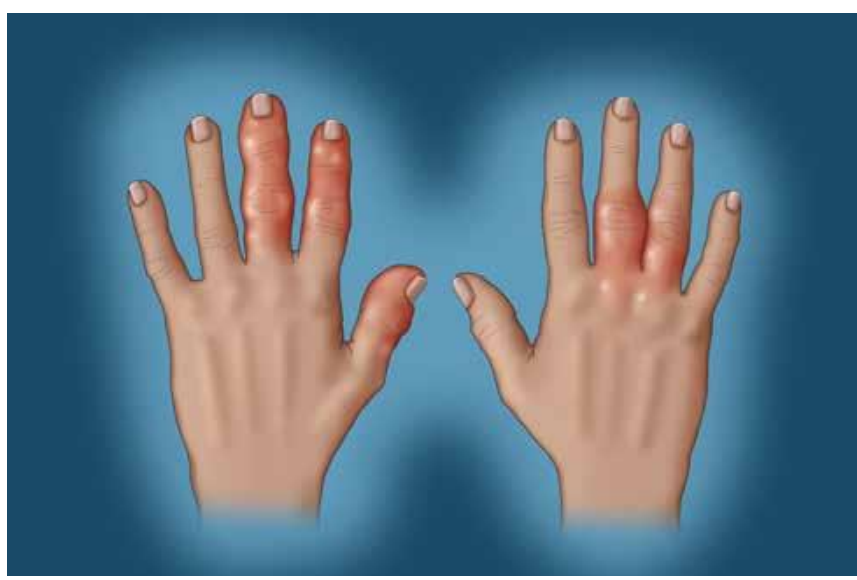
people get older.

Common arthritis joint symptoms include swelling, pain, stiffness and decreased range of motion. Symptoms may come and go. They can be mild, moderate or severe. They may stay about the same for years but can progress or get worse over time. Severe arthritis can result in chronic pain, inability to do daily activities and make it difficult to walk or climb stairs.

Arthritis can cause permanent joint changes. These changes may be visible, such as knobby finger joints, but often the damage can only be seen on X-ray. Some types of arthritis also affect the heart, eyes, lungs, kidneys and skin as well as the joints.

\section{Learning Activities}

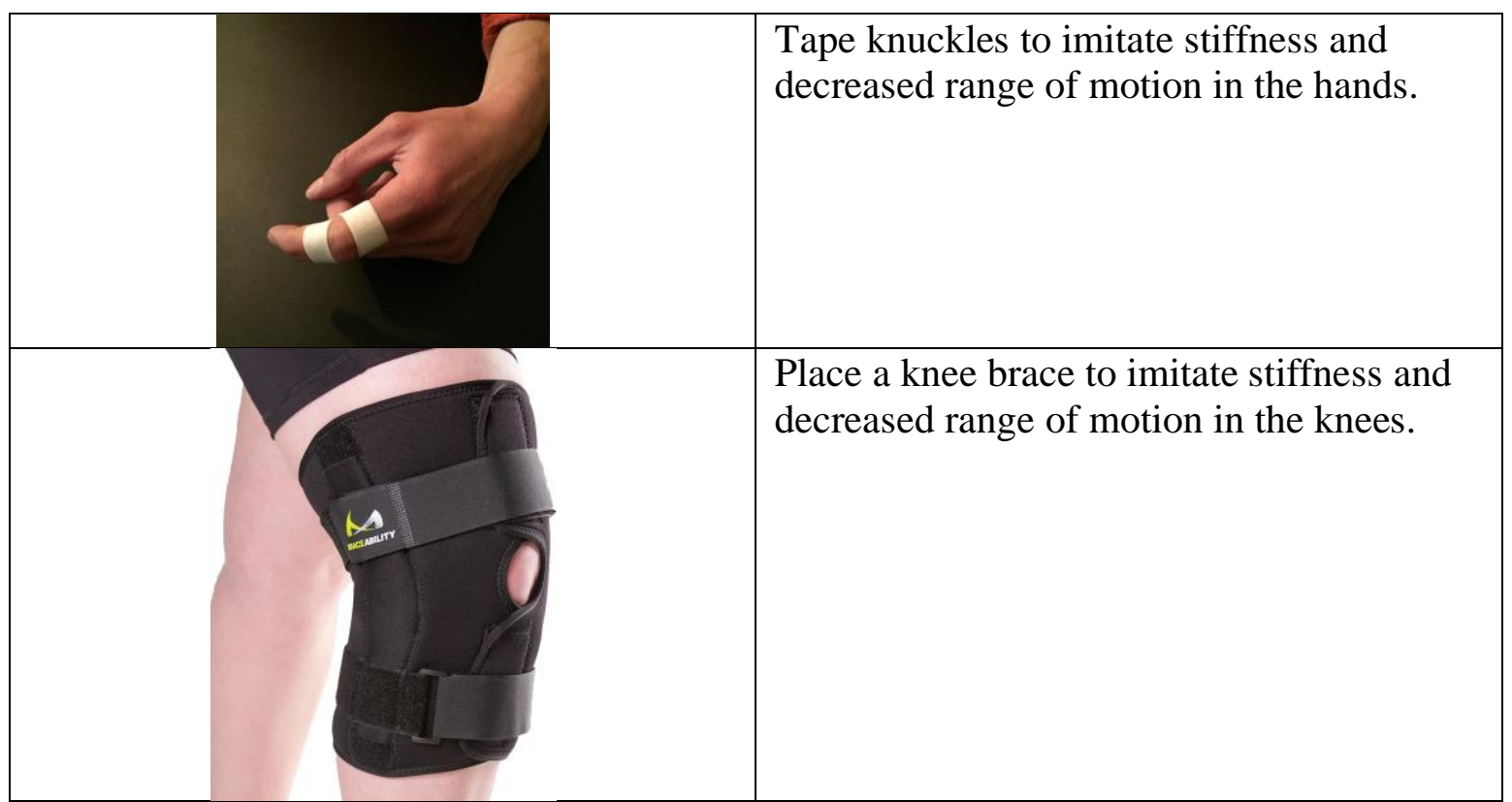




\begin{tabular}{|l|l|}
\hline *Place foot brace on to imitate stiffness and \\
decreased range of motion.
\end{tabular}

\section{References}

Arthritis Foundation. (2020). What is arthritis? Retrieved from https://www.arthritis.org/ health-wellness/about-arthritis/understandingarthritis/what-is-arthritis 


\section{Vestibular Disorders}

The vestibular system includes the parts of the inner ear and brain that help control balance and eye movements. If the system is damaged by disease, aging, or injury, vestibular disorders can result, and are often associated with one or more of these symptoms, among others: vertigo and dizziness, imbalance and spatial disorientation, vision disturbance, hearing changes, cognitive and/or psychological changes, and other symptoms.

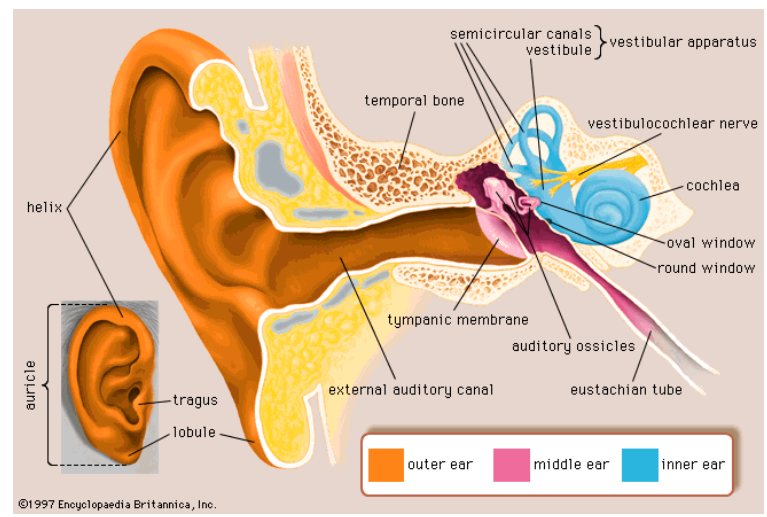

\section{Vertigo and dizziness}

- Symptoms can be present while sitting still, in specific positions, or with movement

- Lightheaded, floating, or rocking sensation (dizziness)

- Sensation of being heavily weighted or pulled in one direction

- Spinning or whirling sensation; a feeling the person or world moving when it is not (vertigo)

\section{Balance and spatial orientation}

- Imbalance, stumbling, difficulty walking straight or when turning

- Clumsiness or difficulty with coordination

- Difficulty maintaining straight posture; head may be tilted to the side

- Tendency to look downward to confirm the location of the ground

- Tendency to touch or hold onto something when standing, or to touch or hold the head while seated

- Sensitivity to changes in walking surfaces or footwear

- Difficulty walking in the dark

- Muscle and joint pain (due to difficulty balancing)

\section{Vision}

- Trouble focusing or tracking objects with the eyes; objects or words on a page seem to jump, bounce, float, or blur or may appear doubled

- Discomfort from busy visual environments such as traffic, crowds, stores, and patterns

- Sensitivity to light, glare, and moving or flickering lights; fluorescent lights may be especially troublesome

- Sensitivity to certain types of computer monitors and digital televisions

- Tendency to focus on nearby objects; increased discomfort when focusing at a distance

- Increased night blindness; difficulty walking in the dark

- Poor depth perception

\section{Hearing changes}

- Hearing loss; distorted or fluctuating hearing

- Tinnitus (ringing, roaring, buzzing, whooshing, or other noises in the ear) 
- Sensitivity to loud noises or environments

- Sudden loud sounds may increase symptoms of vertigo, dizziness, or imbalance

\section{Cognitive}

- Difficulty concentrating and paying attention; easily distracted

- Forgetfulness and short-term memory lapses

- Confusion, disorientation, difficulty comprehending directions or instructions

- Difficulty understanding conversations, especially when there is background noise or movement

- Mental and/or physical fatigue out of proportion to activity

\section{Psychological}

- Loss of self-reliance, self-confidence, self-esteem

- Anxiety, panic, social isolation

- Depression

\section{Other}

- Nausea or vomiting

- "Hangover" or "seasick" feeling in the head

- Motion sickness

- Sensation of fullness in the ears

- Ear pain

- Headaches

- Slurred speech

Learning Activities

\begin{tabular}{|l|l|}
\hline Falking. During this time look downward. \\
wallet brace on to imitate difficulty
\end{tabular}




\begin{tabular}{|l|l|}
\hline $\begin{array}{l}\text { Hold weight (2-3 lbs.) on one side of the } \\
\text { body to imitate sensation of being heavily } \\
\text { weighted or being pulled to one direction. }\end{array}$ \\
\hline $\begin{array}{l}\text { Place ear buds in to imitate a buzzing noise } \\
\text { or play podcast on low volume to } \\
\text { demonstrate difficulty with background } \\
\text { noise. }\end{array}$ \\
\hline $\begin{array}{l}\text { *Spin around 3-5 times to imitate dizziness. } \\
\text { Please perform this in an open grass area } \\
\text { and understand your limitations. }\end{array}$ \\
\hline
\end{tabular}

\section{References}

VEDA Life Rebalance. (2020). About vestibular disorders. Retrieved from https://vestibular.org/understanding-vestibular-disorder/symptoms 


\section{Proprioception Disorder}

Proprioception, also called kinesthesia, is the body's ability to sense its location, movements, and actions. It's the reason we're able to move freely without consciously thinking about our environment.

Examples of proprioception include being able to walk or kick without looking at your feet or being able touch your nose with your eyes closed.

Injuries or medical conditions that affect the muscles, nerves, and the brain can cause longterm or permanent proprioception impairment.

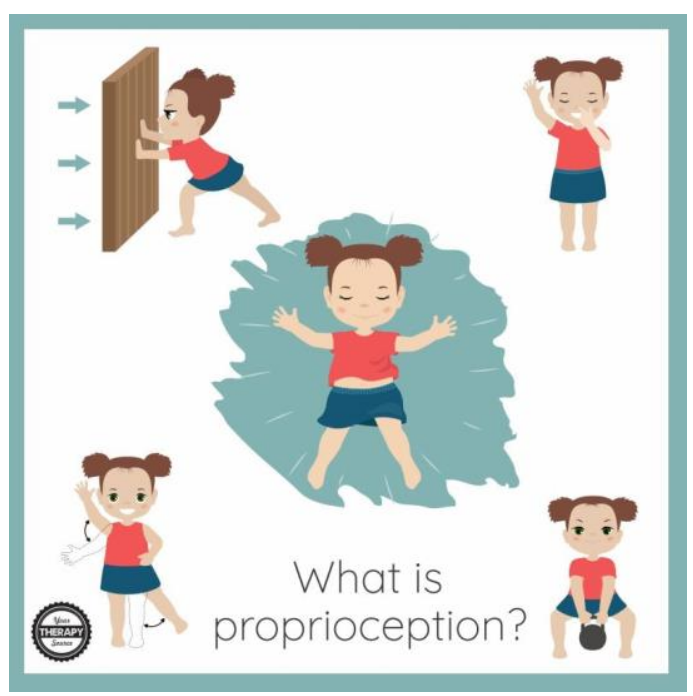
Age-related changes also affect proprioception.

Proprioception is basically a continuous loop of feedback between sensory receptors throughout your body and your nervous system.

Sensory receptors are located on your skin, joints, and muscles. When we move, our brain senses the effort, force, and heaviness of our actions and positions and responds accordingly.

Abnormal proprioception causes symptoms that can interfere with even the simplest activities. Symptoms include:

- Balance issues, such as having trouble standing on one foot or frequent falls while walking or sitting

- Uncoordinated movement, such as not being able to walk in a straight line

- Clumsiness, such as dropping or bumping into things

- Poor postural control, such as slouching or having to place extra weight on a table for balance while sitting

- Trouble recognizing your own strength, such as pressing on a pen too hard when writing or not being able to gauge the force needed to pick something up

- Avoiding certain movements or activities, such as climbing stairs or walking on uneven surfaces because of a fear of falling 


\section{Learning Activities}

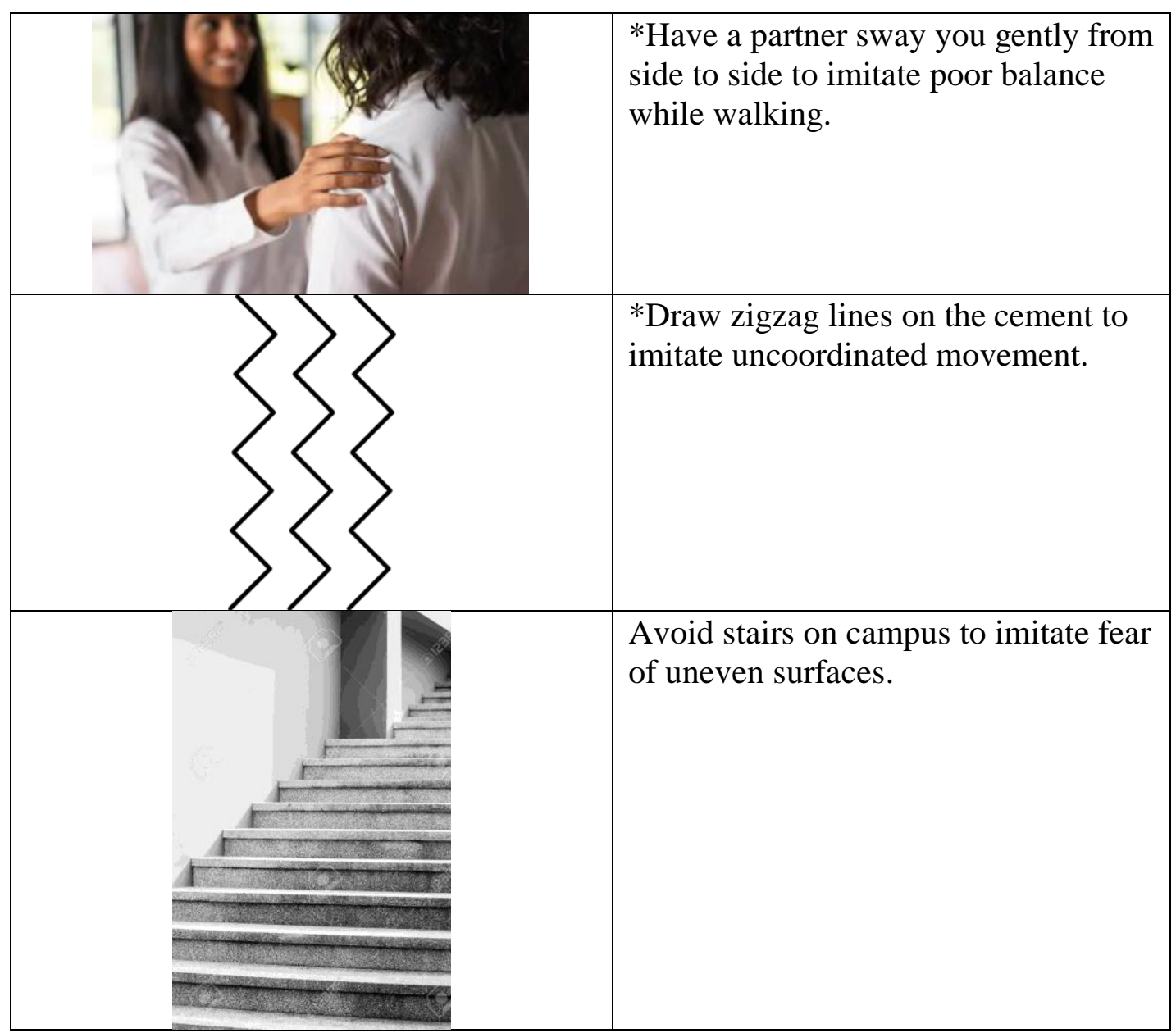

\section{References}

Healthline Media a Red Ventures Company. (2020). What is proprioception, and why is it so important? Retrieved from https://www .healthline.com/ health/body/ proprioception 


\section{Sensory Processing Disorder}

Sensory processing (originally called "sensory integration dysfunction" or SID) refers to the way the nervous system receives messages from the senses and turns them into appropriate motor and behavioral responses. Whether you are biting into a sandwich, riding a bicycle, or reading a book, your successful completion of the activity requires accurate processing of sensation.

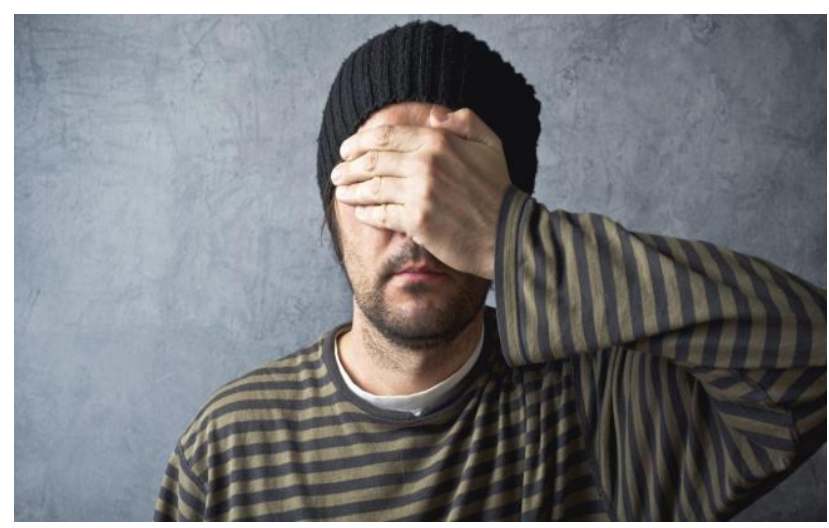

Sensory Processing Disorder (SPD), exists when sensory signals are either not detected or don't get organized into appropriate responses. Pioneering occupational therapist, educational psychologist, and neuroscientist A. Jean Ayres, $\mathrm{PhD}$, likened SPD to a neurological "traffic jam" that prevents certain parts of the brain from receiving the information needed to interpret sensory information correctly. A person with SPD finds it difficult to process and act upon information received through the senses, which creates challenges in performing countless everyday tasks. Motor clumsiness, behavioral problems, anxiety, depression, school failure, and many other problems may impact those who do not have effective treatment.

\section{Adults with SPD may exhibit the following signs:}

- Feeling that a shade is pulled over the outside world

- Experiencing muted sights, sounds, and touch

- Frequent feelings of sensory overload

- Avoid visually stimulating environments and sounds

- Feeling lethargic and slow in the start of the day

- Inappropriate amount of force when handling objects

- Begin new tasks simultaneously and leave many of them uncompleted

- Difficulty learning new motor tasks, or sequencing steps of task

- Need physical activities to help maintain focus throughout the day

- Misinterpret questions and request, requiring more clarification

- Difficulty reading, reading several times

- Lack of fluency in speech 


\section{Learning Activities}

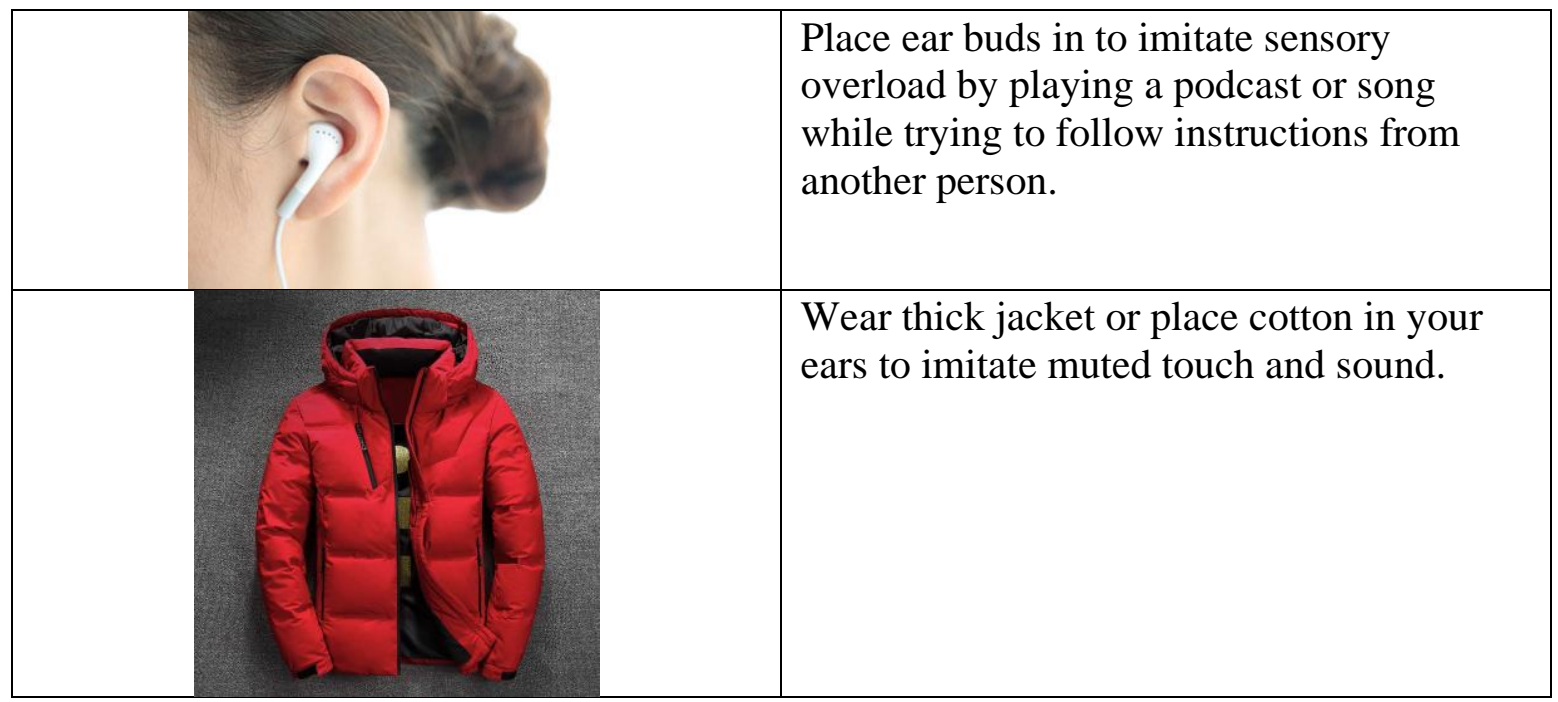

\section{References}

New Hope Media LLC. (2020). Signs of sensory processing disorder (SPD) in adults. Retrieved from https://www.additudemag.com/sensory-processing-disorder-inadults/

STAR Center Foundation. (2020). About SPD. Retrieved from https: //www.spdstar.org /basic /about-spd 


\section{Strategies for Clients}

$>$ Wear supportive shoes

$>$ Avoid uneven terrains

$>$ Wrap foam, cloth, or tape around harness handle to reduce hand stiffness

Alternate between sitting and light stretching

$>$ Keep a backpack of necessary items (water bottle, identification, medication, light jacket, snack, disposable heat pads, disposable instant cold pack, sunscreen, sunglasses)

$>$ Get up slowly from sit to stand position and vice versa

$>$ Be aware of the environment if seating is needed

$>$ Use aromatherapy (essential oils), listening to music, or noise canceling headphone to reduce stress during breaks

$>$ Wear a scarf to cover your nose for overwhelming smells

$>$ Wear comfortable/breathable clothing

\section{Strategies for Instructors}

Encourage good posture

$>$ Take frequent breaks (every 20 minutes)

$>$ Check-in with clients during and after different routes

$>$ Choose less hectic and crowded times to go out for practice

$>$ Use clear and concise words

$>$ Consistently use words of encouragement

$>$ Allow clients time to ask questions

$>$ Quiz the group as a whole 


\section{References}

American Occupational Therapy Association. (2020). Occupational therapy using a sensory integration-based approach with adult populations. Retrieved from https://www.aota.org/About-Occupational-Therapy/Professionals/HW/UsingSensory-Integration-Based-Approach-With-Adult-Populations.aspx

Fitbit Inc. (2018). The 5-minute stretching routine that will keep you walking strong. Retrieved from https://blog.fitbit.com/stretching-routine-for-walkers/

Mayo Foundation for Medical Education and Research. (2020). Rheumatoid arthritis pain: Tips for protecting your joints. Retrieved from https://www.mayoclinic.org /diseases-conditions/rheumatoid-arthritis/in-depth/arthritis/art-20047954

New Hope Media LLC. (2020). How to treat sensory processing disorder. Retrieved from https://www.additudemag.com/sensory-processing-disorder-treatment/

U.S. Department of Health \& Human Services. (2020). 5 proven ways to manage arthritis. Retrieved from https://www.cdc.gov/arthritis/basics/management.htm

Veritas Health, LLC. (2020). Physical and occupational therapy offer benefits for neuropathic pain. Retrieved from https://www.spine-health.com/treatment/painmanagement/physical-and-occupational-therapy-offer-benefits-neuropathic-pain 